\title{
Space Suit Portable Life Support System Test Bed (PLSS 1.0) Development and Testing
}

\author{
Carly Watts ${ }^{1}$ and Colin Campbell ${ }^{2}$ \\ NASA Johnson Space Center, Houston, TX, 77058 \\ and \\ Matthew Vogel $^{3}$ and Bruce Conger ${ }^{4}$ \\ Jacobs Engineering, Engineering and Science Contract Group, Houston, TX, 77058
}

\begin{abstract}
A multi-year effort has been carried out at NASA Johnson Space Center to develop an advanced extravehicular activity (EVA) Portable Life Support System (PLSS) design intended to further the current state of the art by increasing operational flexibility, reducing consumables, and increasing robustness. Previous efforts have focused on modeling and analyzing the advanced PLSS architecture, as well as developing key enabling technologies. Like the current International Space Station Extravehicular Mobility Unit PLSS, the advanced PLSS comprises three subsystems required to sustain the crew during EVA, including the Thermal, Ventilation, and Oxygen Subsystems. This effort has culminated in the construction and operation of PLSS 1.0, a test bed that simulates full functionality of the advanced PLSS design. PLSS 1.0 integrates commercial off-the-shelf hardware with prototype technology development components, including the primary and secondary oxygen regulators, Ventilation Subsystem fan, Rapid Cycle Amine swingbed carbon dioxide and water vapor removal device, and Spacesuit Water Membrane Evaporator heat rejection device. The overall PLSS 1.0 test objective was to demonstrate the capability of the Advanced PLSS to provide key life support functions including suit pressure regulation, carbon dioxide and water vapor removal, thermal control, and contingency purge operations. Supplying oxygen was not one of the specific life support functions because the PLSS 1.0 test was not oxygen rated. Nitrogen was used for the working gas. Additional test objectives were to confirm PLSS technology development components performance within an integrated test bed, indentify unexpected system-level interactions, and map the PLSS 1.0 performance with respect to key variables such as crewmember metabolic rate and suit pressure. Successful PLSS 1.0 testing completed 168 test points over 44 days of testing and produced a large database of test results that characterize system-level and component performance. With the exception of several minor anomalies, the PLSS 1.0 test rig performed as expected; furthermore, many system responses trended in accordance with pre-test predictions.
\end{abstract}

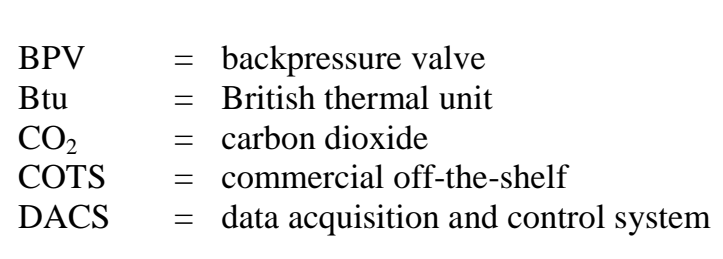

\section{Nomenclature}

${ }^{1}$ Aerospace Technologist, 2101 NASA Parkway, Houston, TX, 77058/Mail Stop EC5, nonmember

${ }^{2}$ Aerospace Technologist, 2101 NASA Parkway, Houston, TX, 77058/Mail Stop EC5, nonmember

${ }^{3}$ Thermal Analyst, 2224 Bay Area Blvd., Houston, TX, 77058/Mail Stop JE-5EA, member

${ }^{4}$ Lead Thermal Analyst, 2224 Bay Area Blvd., Houston, TX, 77058/Mail Stop JE-5EA, nonmember

1

American Institute of Aeronautics and Astronautics 


$\begin{array}{ll}\Delta \mathrm{P} & =\text { delta pressure } \\ \mathrm{EMU} & =\text { Extravehicular Mobility Unit } \\ \mathrm{EVA} & =\text { extravehicular activity } \\ \mathrm{GN}_{2} & =\text { gaseous nitrogen } \\ \mathrm{HMS} & =\text { Human Metabolic Simulator } \\ \mathrm{H}_{2} \mathrm{O} & =\text { water vapor } \\ \mathrm{ISS} & =\text { International Space Station } \\ \mathrm{JSC} & =\text { Johnson Space Center } \\ \mathrm{kPa} & =\text { kilopascal } \\ \mathrm{LCGS} & =\text { liquid cooling garment simulator } \\ \mathrm{Lpm} & =\text { Liters per minute } \\ \mathrm{MGC} & =\text { metabolic gas consumption } \\ \mathrm{Mm} \mathrm{Hg} & =\text { millimeters of mercury } \\ \mathrm{MPa} & =\text { megapascal } \\ \mathrm{mV} & =\text { millivolt } \\ \mathrm{OS} & =\text { Oxygen Subsystem } \\ \mathrm{Pa} & =\text { pascal } \\ \mathrm{P} \mathrm{CO} 2 & =\text { Partial pressure of carbon dioxide } \\ \mathrm{PGS} & =\text { Pressure Garment System } \\ \mathrm{PGSVS} & =\text { Pressure Garment System volume simulator } \\ \mathrm{PLSS} & =\text { Portable Life Support System } \\ \mathrm{POA} & =\text { Primary Oxygen Assembly } \\ \mathrm{POR} & =\text { Primary Oxygen Regulator } \\ \mathrm{POV} & =\text { Primary Oxygen Vessel } \\ \text { psi } & =\text { pounds per square inch } \\ \text { psid } & =\text { pounds per square inch differential } \\ \text { psig } & =\text { pounds per square inch gauge } \\ \mathrm{RCA} & =\text { Rapid Cycle Amine } \\ \mathrm{RH} & =\text { Relative humidity } \\ \mathrm{SSA} & =\text { Space Suit Assembly } \\ \mathrm{SOA} & =\text { Secondary Oxygen Assembly } \\ \mathrm{SOR} & =\text { Secondary Oxygen Regulator } \\ \mathrm{SOV} & =\text { Secondary Oxygen Vessel } \\ \mathrm{SWME} & =\text { Spacesuit Water Membrane Evaporator } \\ \mathrm{TP} & =\text { test point } \\ \mathrm{TS} & =\text { Thermal Subsystem } \\ \mathrm{VS} & =\text { Ventilation Subsystem } \\ \mathrm{W} & =\text { Watt } \\ & \end{array}$

\section{Introduction}

Gor several years, a concerted effort at NASA Johnson Space Center (JSC) has worked to advance extravehicular activity (EVA) Portable Life Support System (PLSS) technology at the system level as well as on a component level. The overall objective of these efforts was to develop an advanced PLSS that meets or exceeds the current Space Shuttle/International Space Station (ISS) Extravehicular Mobility Unit (EMU) PLSS performance while increasing robustness and flexibility and decreasing consumables. The complexity of a PLSS meant that this concerted effort actually consisted of multiple interrelated parallel efforts. To date, system-level efforts have been analytical in nature, assessing the feasibility of new system designs given new component technologies as well as helping define requirements or goals that PLSS component developmental prototypes need to meet. PLSS component level efforts, however, have been primarily experimental, focusing on producing and testing technology development components. The results of these parallel system and component efforts are captured by the new PLSS design that is periodically updated and designated as the Advanced PLSS.

These multi-year PLSS developmental efforts have culminated into an integrated test bed that fully simulates the Advanced PLSS functionality while incorporating five key PLSS technology development components. This test bed is the first time since the Space Shuttle EMU PLSS development that an integrated PLSS test bed has been built 
and operated. The Advanced PLSS test bed, named PLSS 1.0, consisted of the three PLSS subsystems including the Oxygen Subsystem, Ventilation Subsystem, and Thermal Subsystem and ancillary equipment that facilitated testing. PLSS technology development components used in PLSS 1.0 are at various technology-readiness levels and include the Oxygen Subsystem Primary and Secondary Oxygen Regulators (POR/SOR), Ventilation Subsystem Rapid Cycle Amine (RCA) swingbed, Ventilation Subsystem fan, and Thermal Subsystem Spacesuit Water Membrane Evaporator (SWME). It should be noted the PLSS 1.0 test bed was not oxygen rated and used nitrogen as the working gas.

The overall PLSS 1.0 test objective was to demonstrate the capability of the Advanced PLSS to provide key life support functions that a PLSS must provide. These functions included suit pressure regulation, carbon dioxide $\left(\mathrm{CO}_{2}\right)$ and water $\left(\mathrm{H}_{2} \mathrm{O}\right)$ removal, thermal control, and contingency purge operations. Derived from the overall test objective were numerous specific test objectives that can be summarized as follows:

- Confirming technology development components perform in a system-level test as they have performed during component-level testing

- Identifying unexpected system-level interactions

- Operating PLSS 1.0 in nominal steady-state EVA modes to baseline subsystem performance with respect to metabolic rate, suit pressure and flow rate, and environmental conditions

- Simulating nominal transient EVA operational scenarios

- $\quad$ Simulating contingency EVA operational scenarios

- Further evaluating PLSS technology development components

PLSS 1.0 testing was performed at JSC from June 17 to September 30, 2011. A total of 168 test points, classified as steady state or transient, were completed over 44 days of testing. Whereas all test points simultaneously served multiple specific test objectives, steady-state test points primarily addressed the PLSS 1.0 baseline performance and technology development component performance objectives, and transient test points primarily focused on nominal and contingency EVA operational scenarios.

\section{An Overview of the Advanced Portable Life Support System}

The PLSS 1.0 test was based on Revision C of the Advanced PLSS schematic, which is presented in Fig. 1 as it is contained in Ref. 1. Potential missions for the Advanced PLSS are low-Earth orbit, lunar, Mars, asteroid, and Langrangian point EVA operations. Like the EMU PLSS, the Advanced PLSS has Oxygen, Ventilation, and Thermal Subsystems that provide the same life support functions as in the EMU PLSS. 


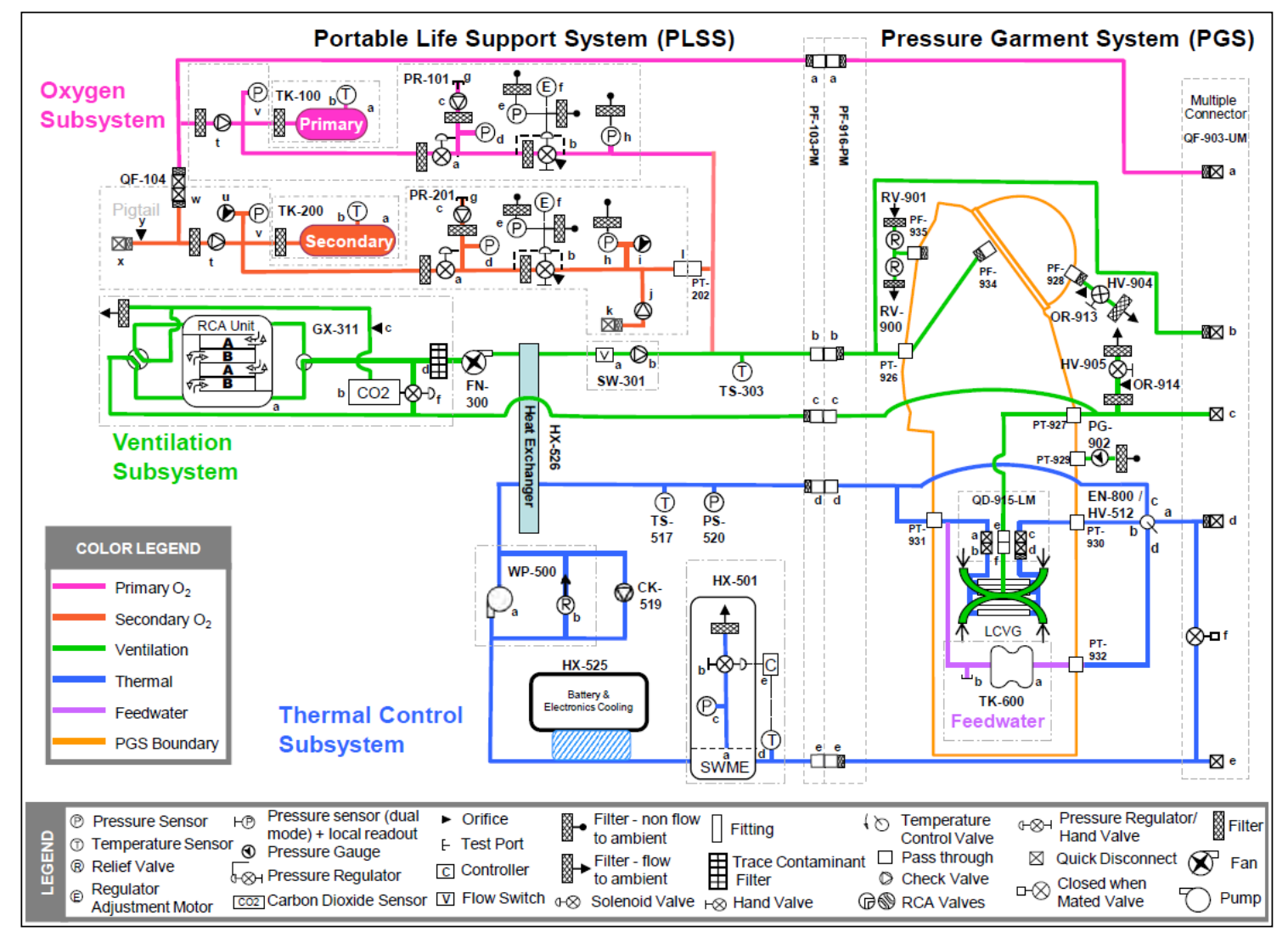

Figure 1. Advanced PLSS schematic, Revision C.

The Oxygen Subsystem stores oxygen and regulates the supply of oxygen to maintain the suit pressure while simultaneously matching crewmember oxygen consumption and suit leakage. The space suit was referred to as the Pressure Garment Subsystem (PGS) per an older nomenclature. The terms PGS, space suit, and suit will be used interchangeably throughout this document. The Oxygen Subsystem also provides backup, emergency high-flow oxygen should a contingency such as a material suit leak occur.

Primary functions of the Ventilation Subsystem include circulating gas through the suit to provide fresh oxygen to the crew and carry away exhaled $\mathrm{CO}_{2}$ and water vapor. The other key Ventilation Subsystem function is to remove the $\mathrm{CO}_{2}$ from the gas stream and maintain humidity levels within the gas stream at acceptable levels. The key functions of the Thermal Subsystem are to provide thermal control for the crew and electronics and to thermally condition the gas stream delivered to crew.

Key differences between the EMU PLSS and Advanced PLSS are in the Oxygen Subsystem oxygen regulation, Ventilation Subsystem $\mathrm{CO}_{2}$ and $\mathrm{H}_{2} \mathrm{O}$ removal, and Thermal Subsystem heat rejection, and fluid transport devices. Starting with the last, the Advanced PLSS splits the Ventilation Subsystem gas and Thermal Subsystem water transport functions among a fan and water pump, respectively, whereas the EMU PLSS combines those functions into one unit (fan/pump/separator). The key benefit of the Advanced PLSS approach was the potential for up to 50\% power savings over the EMU PLSS fluids transport unit. Thermal Subsystem heat rejection of the Advanced and EMU PLSS are performed by a water evaporator and ice sublimator, respectively. Unlike the ice sublimator, water evaporators can work at atmospheric pressures expected on Mars, continuously degas the coolant, and are relatively insensitive to water contaminants. The latter benefit eliminates the need for a strictly controlled and separate water feed system that currently exists in the EMU PLSS. Advanced $\mathrm{PLSS} \mathrm{CO}_{2}$ and $\mathrm{H}_{2} \mathrm{O}$ removal is performed by an RCA swingbed device that instantly regenerates alternate beds by exposure to vacuum, thus eliminating the need for lithium hydroxide consumables or metal oxide high temperature bakeouts currently required by the EMU PLSS. Finally, Advanced PLSS oxygen regulation is provided by variable regulators that have about 4000 setpoints over 
the suit design pressure range. Variable pressure setpoint regulators permit decompression sickness operations while the crewmember is still in the suit. Another benefit is the mission flexibility afforded by the ability to vary suit pressure over the course of an EVA to reduce prebreathe time while simultaneously maximizing suit mobility.

\section{PLSS 1.0 Test Bed}

An overview of the PLSS 1.0 test bed, which was housed in Building 220 at JSC, is presented in Fig. 2. Major PLSS 1.0 test bed segments included representation of the Advanced PLSS and its hardware stand as well as ancillary equipment including the PGS volume simulator (PGSVS), Human Metabolic Simulator (HMS), vacuum system, 6K Gaseous Nitrogen Charging Rig, data acquisition and control system (DACS), and X-38 accumulator based feedwater system. The functional layout of PLSS 1.0 presented in Fig. 3 highlights the PLSS subsystems and key ancillary hardware. It needs to be made clear that the PLSS 1.0 test bed was not oxygen rated. Nitrogen was always used in place of oxygen, hence the need for the nitrogen charging rig.

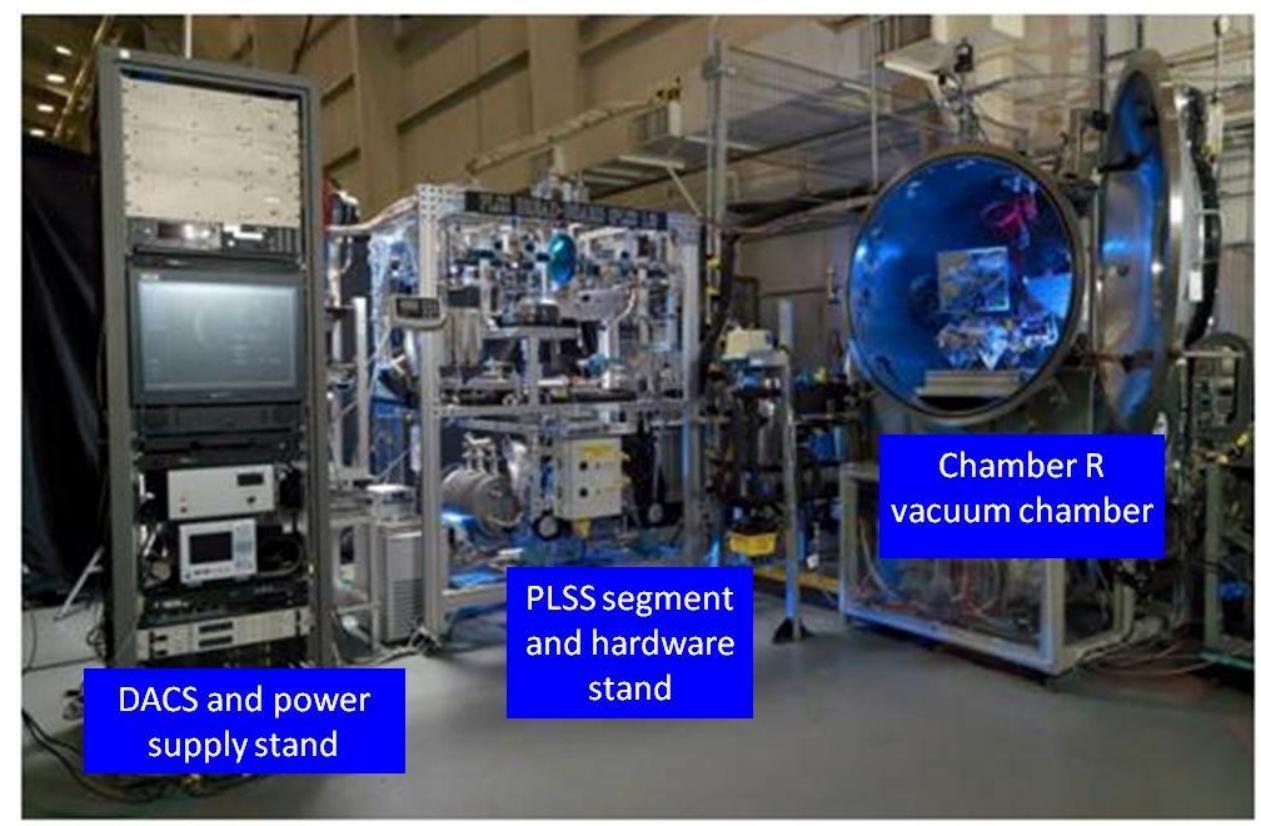

Figure 2. PLSS 1.0 test bed overview. 


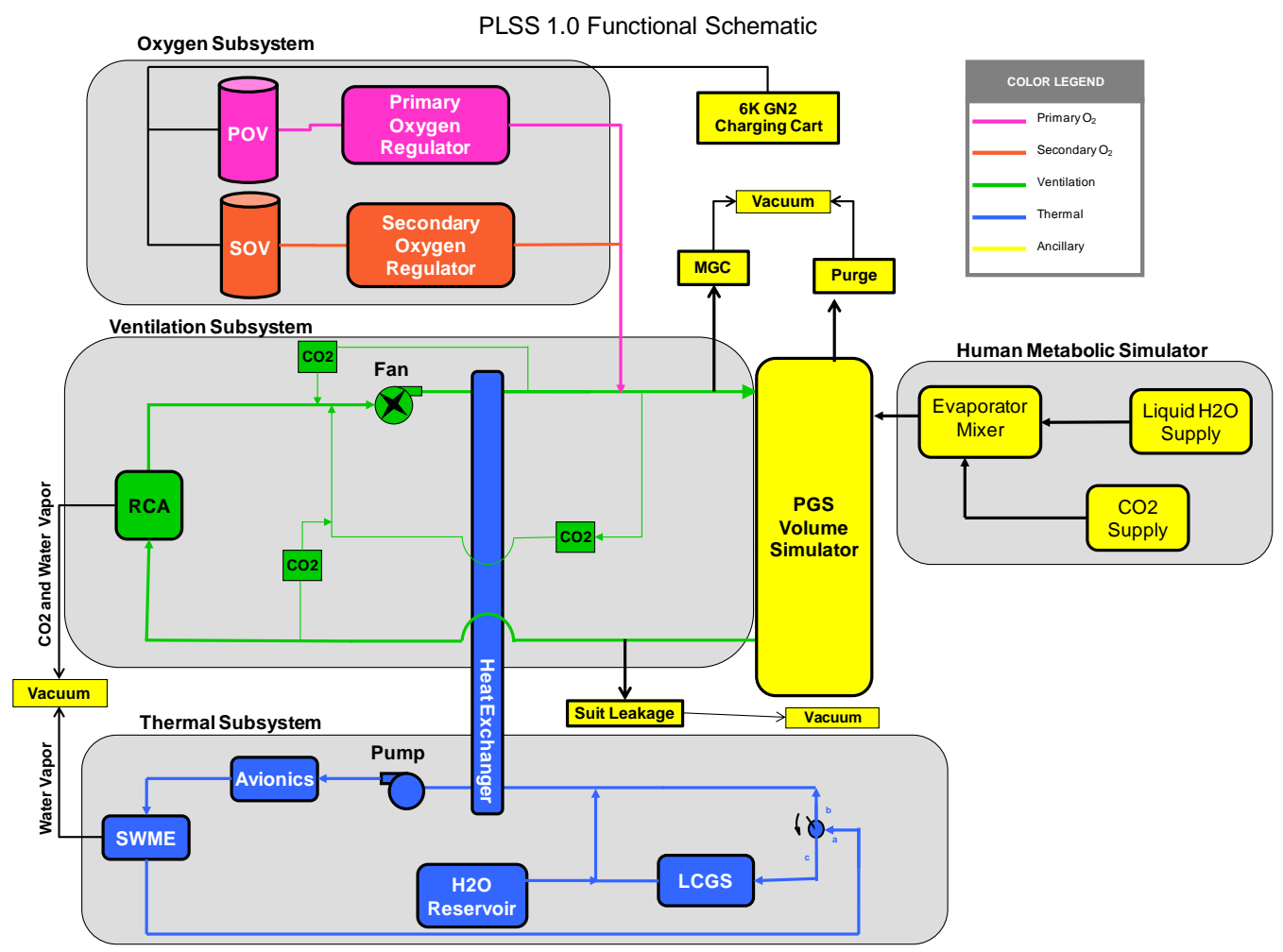

Figure 3. PLSS 1.0 functional schematic.

\section{A. Description of Critical Portable Life Support System Segment Hardware}

This section highlights critical hardware, technology development or commercial off-the-shelf (COTS) items, upon which successful PLSS segment operation was dependent. PLSS technology development components included the Oxygen Subsystem regulators, Ventilation Subsystem fan and RCA swingbed, and Thermal Subsystem SWME. COTS components included the Oxygen Subsystem high-pressure vessels, Ventilation Subsystem flow meter, check valve, and PGSVS inlet $\mathrm{CO}_{2}$ sensor, and the Thermal Subsystem pump, water reservoir, and liquid cooling garment simulator (LCGS).

\section{Oxygen Subsystem}

The Oxygen Subsystem consisted of the Primary Oxygen Assembly (POA) and Secondary Oxygen Assembly (SOA) with each using a COTS pressure vessel to store the high-pressure nitrogen and a technology development regulator that metered the gas supply. The Primary Oxygen Vessel (POV) and Secondary Oxygen Vessel (SOV) were carbon composite overwrapped aluminum lined gas cylinders manufactured by Luxfer Gas Cylinders (model L45M-XD) with a nominal $4.7 \mathrm{~L}\left(285 \mathrm{in}^{3}\right)$ volume and manufacture service rating of $31 \mathrm{MPa}$ (4500 psi).

The POA and SOA regulators (POR/SOR), built by Cobham Life Support \& Mission Equipment (Orchard Park, NY) are technology development units featuring a two-stage, variable setpoint design. The first stage of the regulators was designed to reduce the supply gas pressure ranging from 25.86 to $1.72 \mathrm{MPa}$ (3750- to $250 \mathrm{psia}$ ) down to $1.34-1.72 \mathrm{MPa}(200-250 \mathrm{psia})$, whereas the regulator second stage was designed to reduce the gas down to the setpoint pressure delta, which ranged from 0 to $57.9 \mathrm{kPa}$ (0 to $8.4 \mathrm{psid}$ ). The zero-pressure delta setting results in closed regulator seats and no attempt to maintain the Ventilation Subsystem pressure delta. A stepper motor driven mechanism adjusts the pressure delta setpoint over its 0 to $57.9 \mathrm{kPa}$ range of approximately 4000 steps. Once set, power was not required to maintain the pressure delta setting. Mass flow rates of both POR and SOR are designed to range from 0.009 to $2.5 \mathrm{~kg} / \mathrm{hr}$. The POR and SOR designs are very similar and the key difference is how they are nominally used. During an EVA, the POR will be set to an EVA pressure ranging from 28.3 to $55.8 \mathrm{kPa}$ delta (4.1 to $8.1 \mathrm{psid}$ ) and the SOR will nominally be set to $25.5 \mathrm{kPa}$ delta pressure $(3.7 \mathrm{psid})$. Thus, if the POR fails to regulate

6

American Institute of Aeronautics and Astronautics 
suit pressure, the SOR will be to supply oxygen when the suit pressure falls to approximately $25.5 \mathrm{kPa}$ delta. Additional information about the regulators can be found in Refs. 2, 3, and 4.

Figure 4 presents an overview of the two regulators whereas Fig. 5 presents a photograph of the partially built PLSS 1.0 Oxygen Subsystem showing the layout of the vessels, regulators, and regulator vacuum chambers. Independent regulator vacuum chambers, used to provide the needed pressure reference, were selected to minimize gas line tubing lengths between the vessels and regulators and to allow flexible, independent operations.
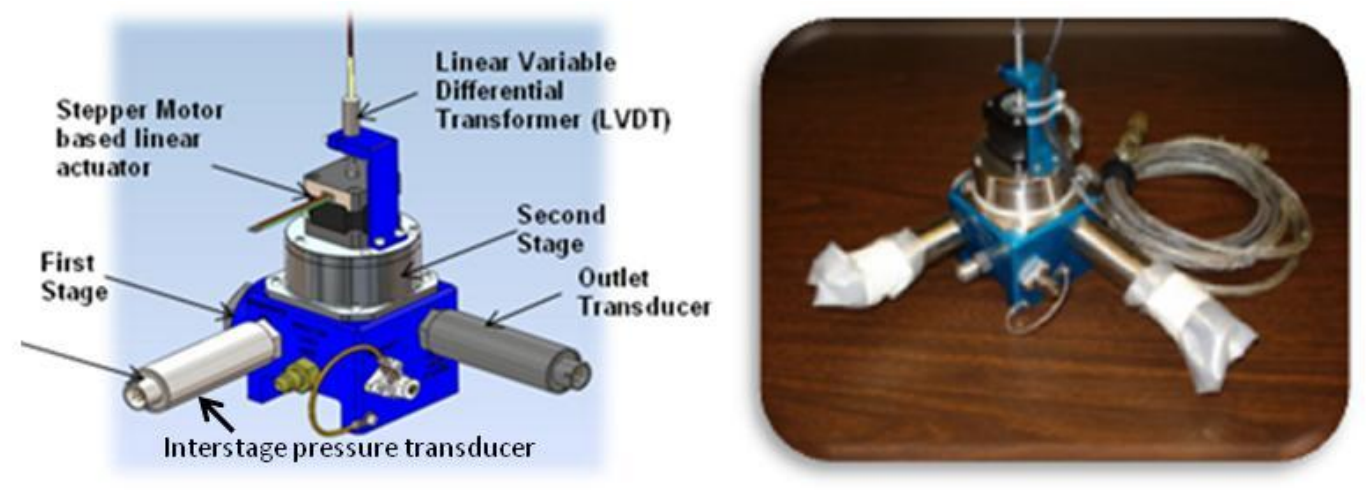

Figure 4. Overview of the PLSS 1.0 Oxygen Subsystem POR and SOR.

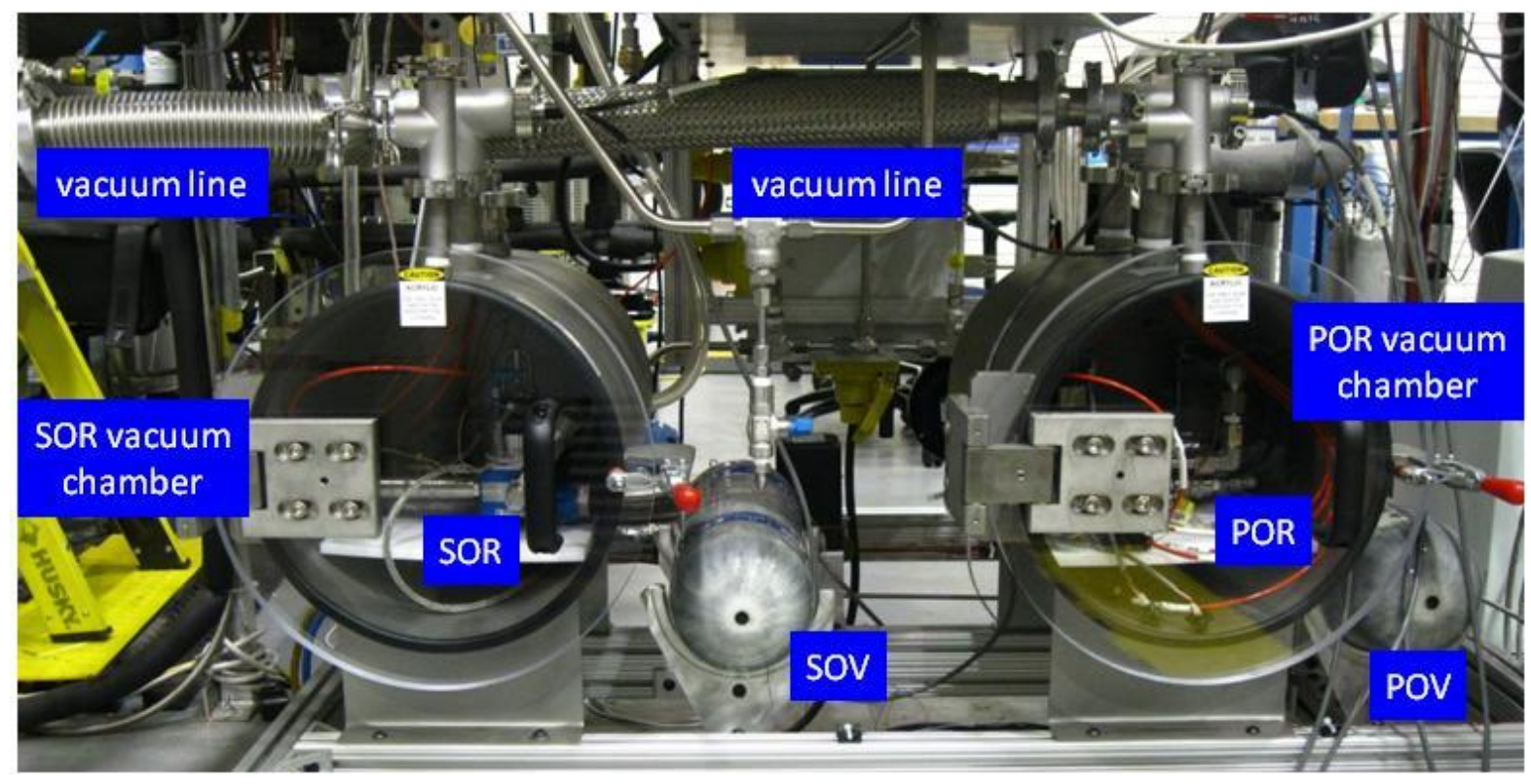

Figure 5. Partial buildup of the PLSS 1.0 Oxygen System. 


\section{Ventilation Subsystem}

Critical Ventilation Subsystem hardware included the fan and RCA swingbed technology development units. The Ventilation Subsystem variable speed fan (see Fig. 6) was designed by Hamilton Sundstrand (Windsor Locks, CT ) as part of a JSC technology development effort. ${ }^{5}$ Two nearly identical units were built by Hamilton Sundstrand with the serial number 1 unit used in PLSS 1.0 testing. Fan performance requirements were to produce 672 $\mathrm{Pa}$ delta-pressure $(\Delta \mathrm{P})$ at $133 \mathrm{Lpm}$

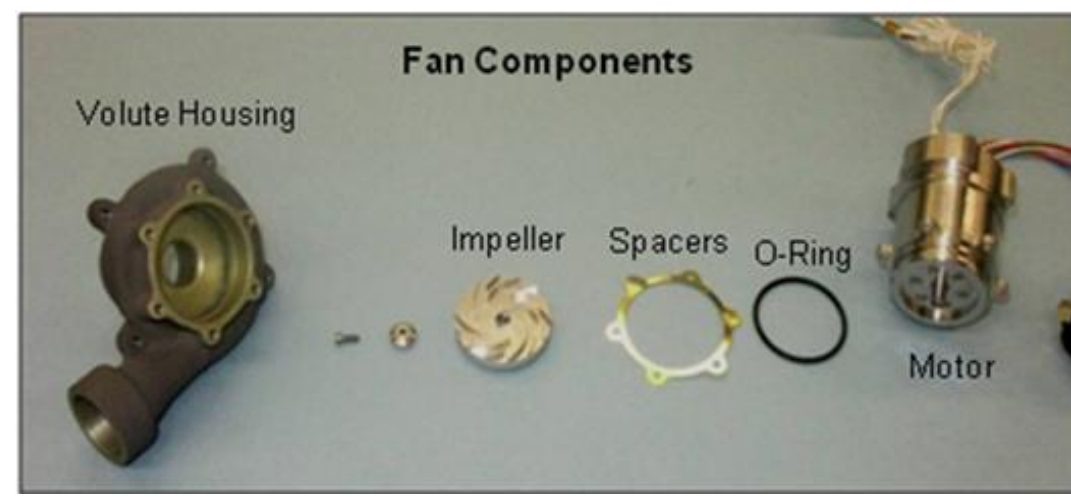

Figure 6. Ventilation Subsystem fan.

flow, $20^{\circ} \mathrm{C}\left(68^{\circ} \mathrm{F}\right)$ inlet oxygen, and $29.65 \mathrm{kPa}$ Ventilation Subsystem loop absolute pressure while consuming no more than $14 \mathrm{~W}$ of total electrical power. In addition to the requirements, fan goals were established for off-nominal conditions such as buddy mode and included generating up to $1681 \mathrm{~Pa} \Delta \mathrm{P}$ at $266 \mathrm{Lpm}$ flow and $26.65 \mathrm{kPa}$ fan inlet absolute pressure. Different fan flow rates are achieved by changing the fan speed via the repackaged COTS controller supplied by Hamilton Sundstrand. Finally, the fan has been subjected to extensive performance testing at Hamilton Sundstrand ${ }^{5}$ as well as at JSC. ${ }^{6}$

Removal of $\mathrm{CO}_{2}$ and $\mathrm{H}_{2} \mathrm{O}$ from the Ventilation Subsystem gas stream was performed by the RCA swingbed (see Fig. 7), another technology development component manufactured by Hamilton Sundstrand. ${ }^{7}$ At the heart of the RCA swingbed is the amine sorbent SA9T that selectively adsorbs $\mathrm{CO}_{2}$ and $\mathrm{H}_{2} \mathrm{O}$ from the gas stream and then readily desorbs them at room temperature when exposed to vacuum. The amine sorbent is packed into two separate sets of individual beds, referred to as Bed A and Bed B, that are cycled between exposure to the Ventilation Subsystem loop gas stream and exposure to vacuum. So when one bed is adsorbing $\mathrm{CO}_{2}$ and $\mathrm{H}_{2} \mathrm{O}$ from the gas stream, the other is releasing those species to vacuum. When commanded, a compressed nitrogen-driven $(\sim 690 \mathrm{kPa}$ gauge, 100 psig) spool valve cycles between the beds. The motive nitrogen is then dumped into the Ventilation Subsystem loop. It should be noted the RCA vacuum porting can be configured several different ways and was mistakenly plumbed into the Ventilation Subsystem loop in a mode, denoted "single ended vacuum inlet". In this mode, only the vacuum port next to the inlet side of the

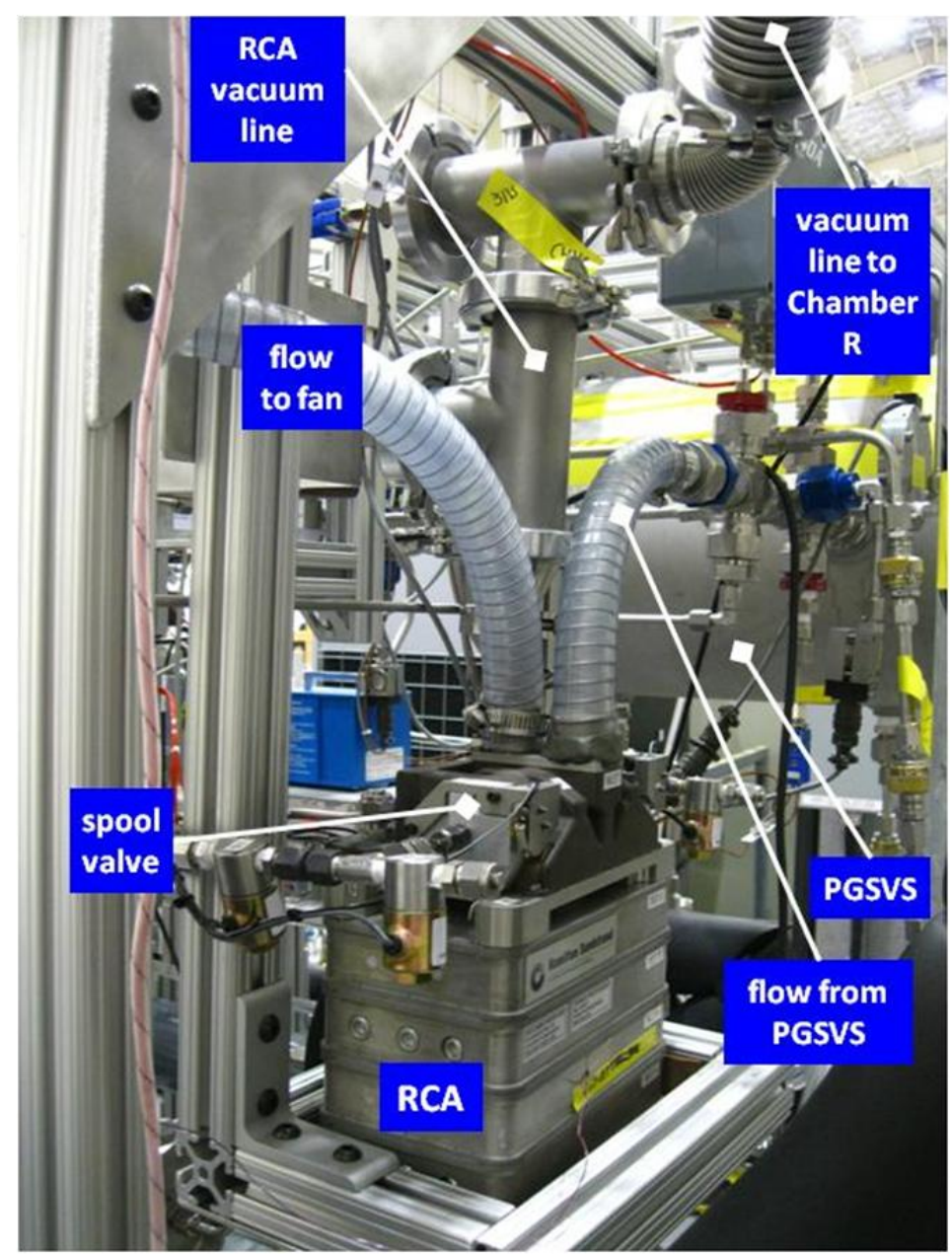

Figure 7. RCA installed in PLSS 1.0

8

American Institute of Aeronautics and Astronautics 
beds was connected to the vacuum system, thus enhancing water adsorption and producing the driest outlet gas conditions possible. It was intended to connect only the vacuum port next to the outlet end of the beds, which would have produced the highest water vapor outlet conditions possible. Finally, the PLSS 1.0 RCA swingbed has been extensively tested at Hamilton Sundstrand and JSC. Further test data and also math model predictions can be found in Refs. 7, 8, and 9.

\section{Thermal Subsystem}

Thermal Subsystem hardware critical for successful test operations include the SWME, pump, liquid/gas heat exchanger, feedwater system, LCGS, and heaters. The PLSS 1.0 SWME, shown in Fig. 8 is a second-generation hollow fiber evaporator that had already undergone extensive component testing immediately prior to PLSS 1.0 testing. ${ }^{10}$ Key benefits of the SWME are attributable to the hydrophobic porous membrane at the heart of the SWME and include insensitivity to coolant contaminants, direct control of coolant outlet temperature, continuous degassing of the coolant, and ability to operate at Mars atmospheric pressures. The first listed benefit means that the SWME does not require highly purified water and a separate feedwater system as currently required by the EMU sublimator. The ability of the SWME to control water outlet temperature results from the use of a backpressure valve (BPV) to change the pressure the hollow fibers outer surface experience by restricting the vapor flow to vacuum. This, in turn, determines how much water can evaporate through the membrane porous walls. Finally, the design requirements of this SWME were to reject $810 \mathrm{~W}$ of heat and maintain a $10^{\circ} \mathrm{C}\left(50^{\circ} \mathrm{F}\right)$ water outlet temperature given $91 \mathrm{~kg} / \mathrm{hr}$ and $17.7^{\circ} \mathrm{C}\left(63.9^{\circ} \mathrm{F}\right)$ inlet flow conditions.

The PLSS 1.0 Thermal Subsystem pump was the COTS variable speed pump used in the first two generations of SWME testing. It is a brushless directcurrent motor, magnetically coupled, external gear pump produced by Micropump, a unit of the IDEX Corporation (Lake Forest, IL). The liquid/gas heat exchanger - a 54 series shell and tube stainless steel heat exchanger, model 00486-1, manufactured by Exergy, LLC (Garden City, NY) - served the purpose of cooling the fan outlet gas so that hot gas

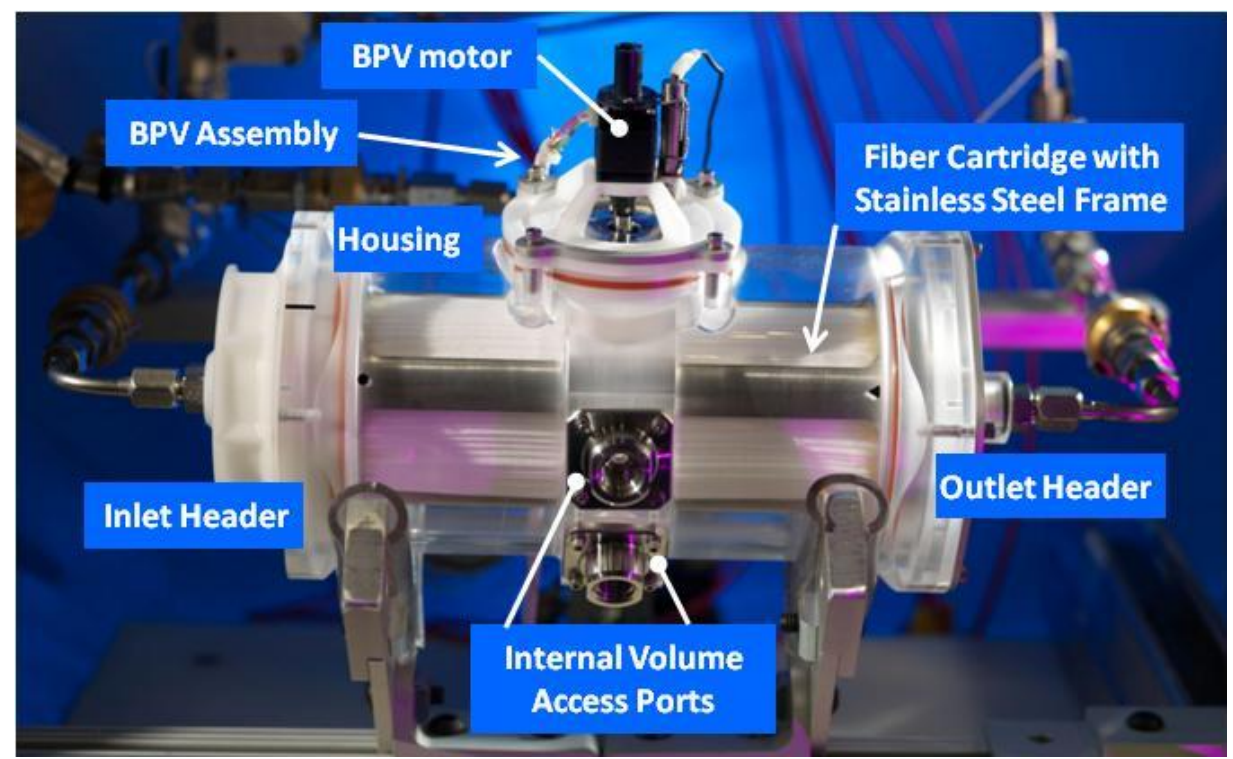

Figure 8. PLSS 1.0 SWME photograph. would not be blown into the PGSVS, the crew and space suit analogy.

The feedwater system, based on a NASA X-38 program Environmental Control and Life Support surplus accumulator, simulated the flexible feedwater bladder envisioned for the Advanced PLSS. The ability of this tank to set the water pressure to levels below one atmosphere mimics how a flexible feedwater bladder stowed inside the space suit would behave. The feedwater system is also referred to as the Thermal Subsystem water reservoir.

The LCGS consisted of a three-way valve, 1000-W inline heater, and ball valve assembled to simulate liquid cooling garment behavior. The heater imposed the crew metabolic heat load plus or minus environmental heat gains or losses, respectively, while the valves were used to split the flow between the LCG and bypass lines and impose an EMU-like pressure drop across the LCGS. Environmental heat gains/losses, mass flow splits, and LCGS pressure drops were derived from EMU Liquid Cooling Ventilation Garment data.

PLSS avionics were simply simulated by a line heater wrapped around the stainless steel tube connecting the pump to the Chamber $\mathrm{R}$ interface. No attempt was made to mimic pressure drop that would be associated with a coldplate. 


\section{B. Ancillary Support Hardware}

1. Pressure Garment System Volume Simulator and Human Metabolic Simulator

The PGSVS simulated the space suit volume where crew metabolic products $\left(\mathrm{CO}_{2}\right.$ and water vapor) mixed with the Ventilation Subsystem gas stream. The mixing volume was a 56.8 L $\left(2 \mathrm{ft}^{3}\right), 316$ stainless steel, American Society of Mechanical Engineers [ASME]-code horizontal pressure tank, model 9934K42, purchased from McMaster-Carr (Elmhurst, IL) (see Fig. 9). Whereas the actual free volume in a suit varies depending on crew, the PGSVS tank replicates a typical volume of the current EMU suit. This tank had seven ports to which the Ventilation Subsystem loop supply and return lines, HMS supply line, Ventilation Subsystem relief valve, condensate trap, and thermocouples were connected.

Crew metabolic production of $\mathrm{CO}_{2}$ and water vapor were implemented as steady gas injections into the PGSVS. The HMS, a collection of flow controllers, and an evaporator produced by Bronkhorst High-Tech B.V. (The Netherlands) performed this steady gas injection. ${ }^{11}$ The HMS worked by controlling $\mathrm{CO}_{2}$ and liquid water flow into the controlled evaporator mixer where a heater maintained temperatures around $99^{\circ} \mathrm{C}\left(210^{\circ} \mathrm{F}\right)$. The mixer internal heater was rated at $100 \mathrm{~W}$, enough to ensure evaporation of the liquid water. Although not shown in Fig. 9, the line from the mixer to the PGSVS was insulated to prevent condensate from forming.

\section{Metabolic Gas Consumption, Suit Leakage, and Suit Purge} Flows

Ventilation Subsystem gas outflows representing metabolic gas consumption (MGC), suit leakage, and suit purge flows were each implemented with a manual hand valve in series with a flow meter.

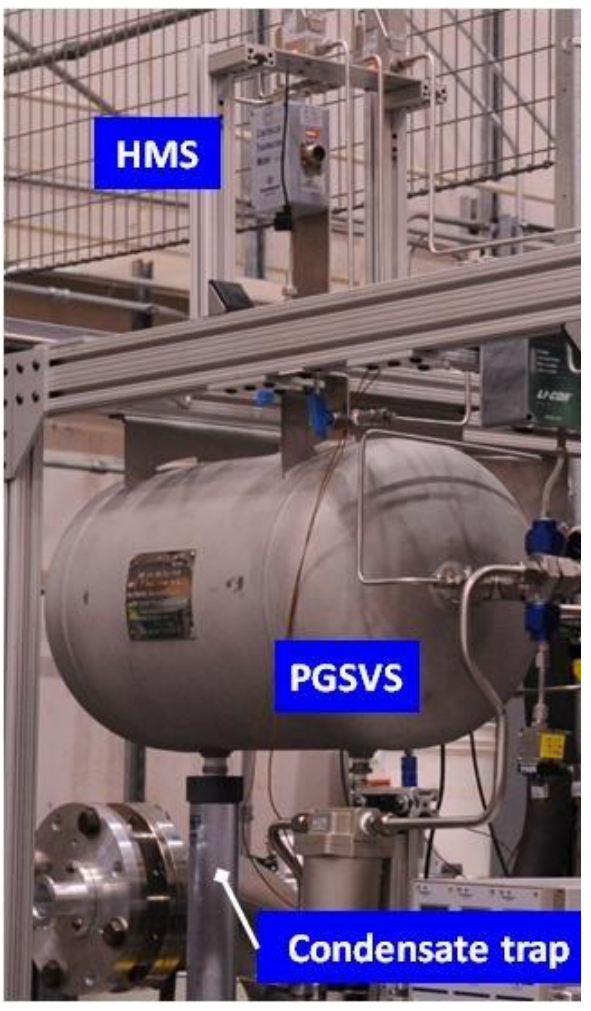

Figure 9. PGS (suit) volume simulator with HMS attached.

Each valve was adjusted as needed to attain the desired flow rate. Because these gas outflows were needed when the Ventilation Subsystem pressure was sub-ambient, the gas outflows were piped to a vacuum source. Care was taken to place the valves downstream of the flow meters so that the meters would be operating at Ventilation Subsystem pressures and not vacuum.

\section{Vacuum System}

The Building 220 vacuum system, powered by two HullVac model HV320 (HullVac Pump Corp, Warminster, PA) rotary piston vacuum pumps and a liquid nitrogen cold trap just upstream of the pumps, was connected to the regulator Laco vacuum chambers (Laco Technologies, Salt Lake City, UT), RCA effluent discharge port, Ventilation Subsystem purge flow line, and Chamber R vacuum chamber, which housed the SWME. A Varian TriScroll vacuum pump (Agilent Technologies, Santa Clara, CA) provided the vacuum source for the MGC and suit leakage lines.

\section{4. $6 K$ GN2 Charging Rig}

Nitrogen required for charging the Oxygen Subsystem vessels was stored in the 6000 psig gaseous nitrogen (6K GN2) charging rig, which consisted of four K-bottles with a 6000 psig pressure rating, needle valves, pressure gauges, a regulator, three relief valves, filters, tubing, flex hoses, and a structural stand. The regulator and two relief valves ensured over pressurization of the Oxygen Subsystem POV and SOV would not occur. 


\section{Data Acquisition and Control System}

The PLSS 1.0 DACS consisted of a National Instruments LabVIEW (Austin, TX) /Microsoft Windows (Microsoft Corporation, Redmond, WA) personal computer front end combined with National Instruments modules required to communicate with more than 100 sensors and hardware components. Table 1 provides a breakdown of the sensor type per PLSS subsystem. Naturally, the PLSS 1.0 instrumentation was comprehensive as was allowed by the fact PLSS 1.0 was a ground test bed that had minimal geometric or footprint limitations. PLSS 1.0 HMS, RCA, and SWME hardware commands were executed via the touch screen (see Fig. 10). In particular, the DACS was used to switch RCA beds, adjust the SWME BPV position, and send $\mathrm{CO}_{2}$ and $\mathrm{H}_{2} \mathrm{O}$ injection setpoints to the HMS. Finally, one of the most useful DACS tools during testing was the large screen

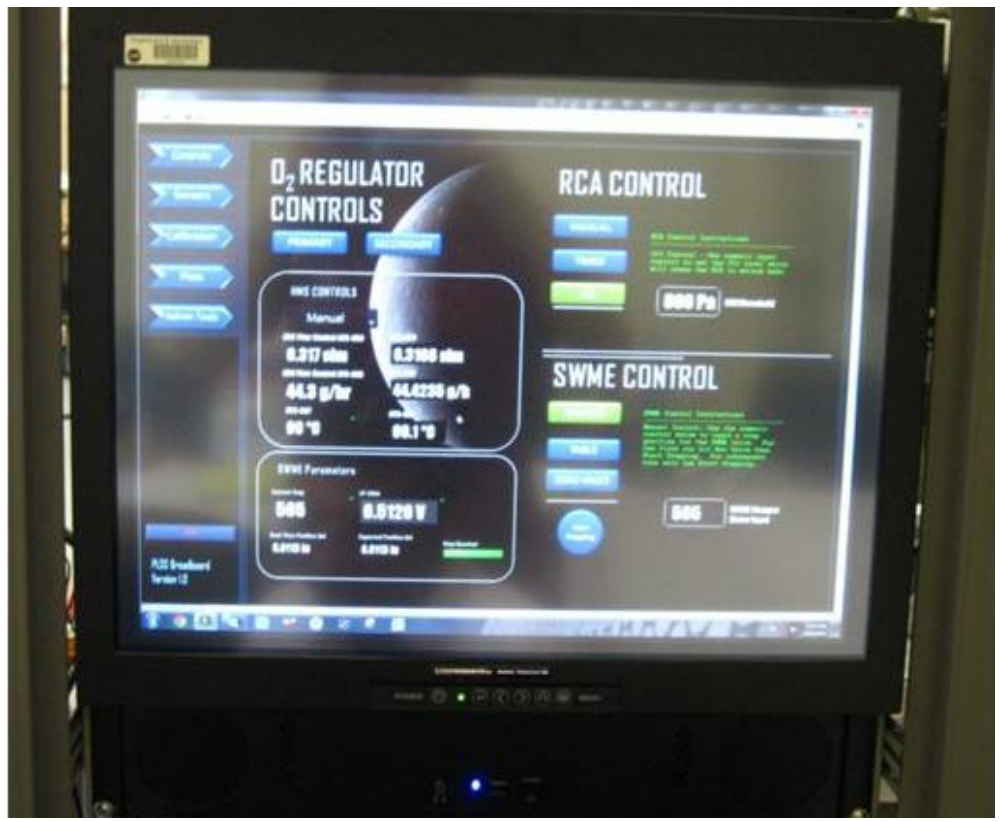

Figure 10. DACS touch screen based graphic user interface. display of sensor data overlayed on the PLSS 1.0 schematic (Fig. 11).

Table 1. PLSS 1.0 DACS Sensors Type and Count per Subsystem

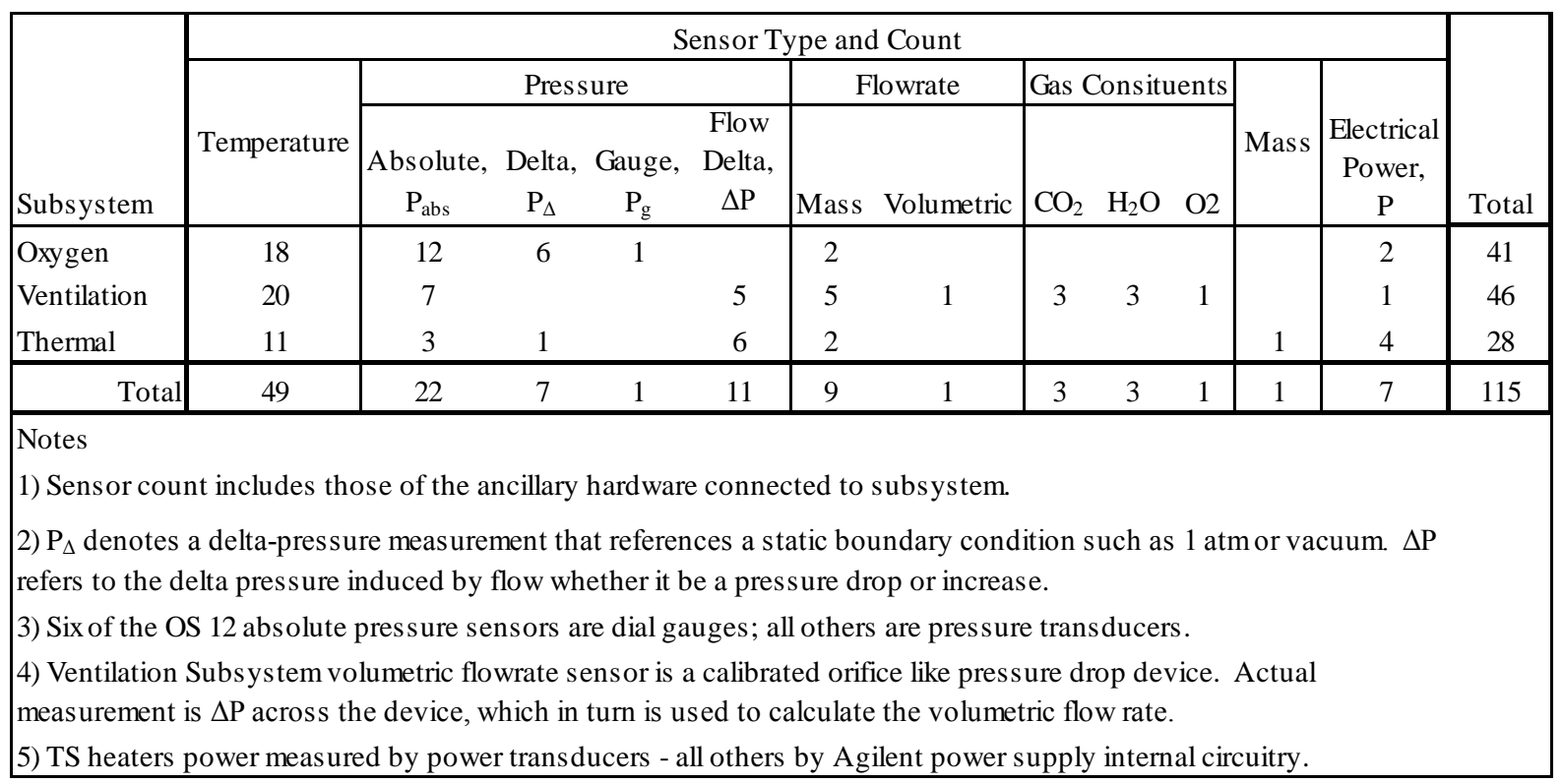




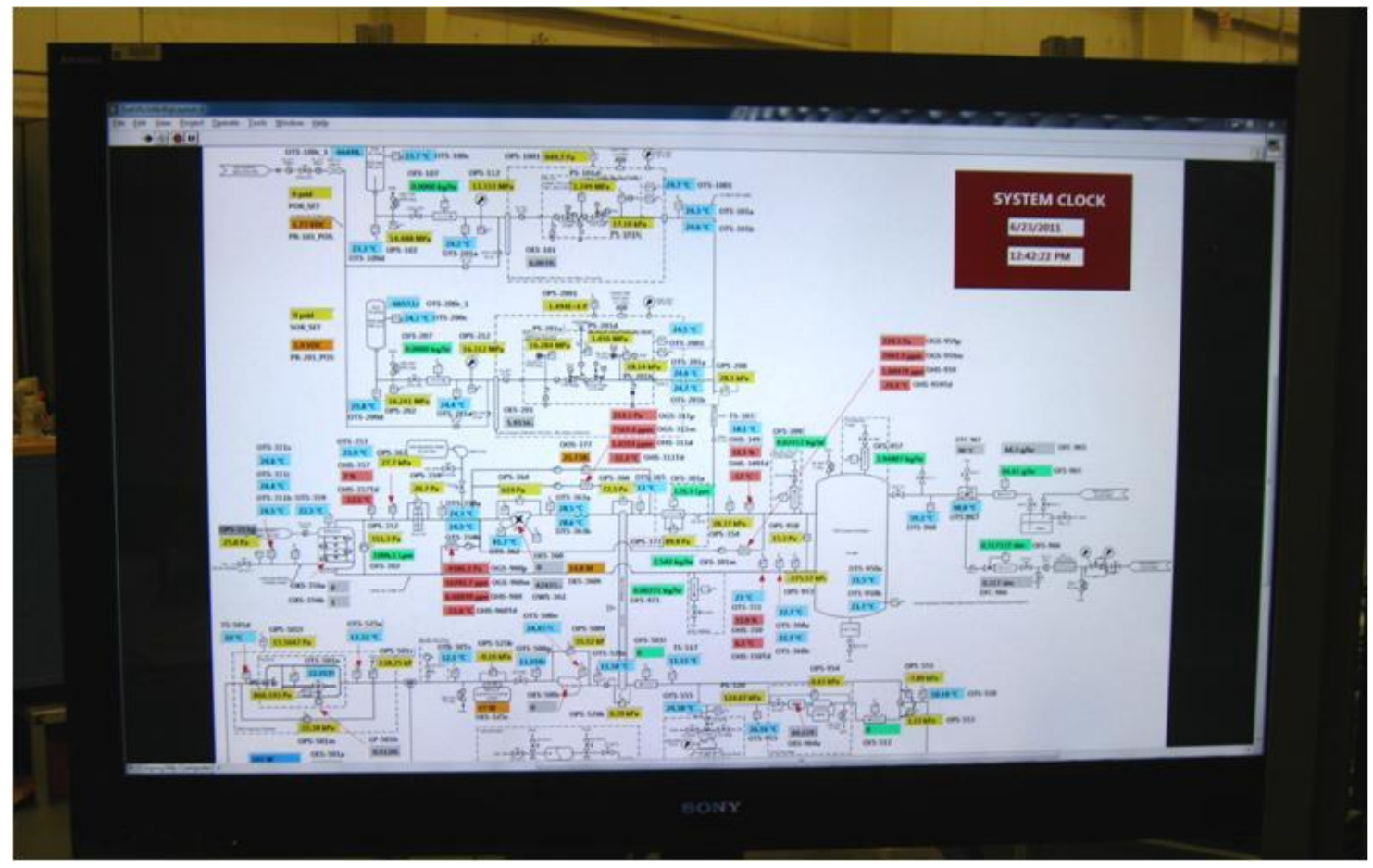

Figure 11. Real-time display of sensor data overlaid on the PLSS 1.0 schematic.

\section{Test Operations}

PLSS 1.0 testing was conducted from June 17 to September 30, 2011, and completed 168 test points over 44 days of testing. Most test points were nominal steady-state simulations that attempted to characterize the PLSS 1.0 performance and/or individual component performance with respect to one or more variables. The most common variable regarding steady-state test points was the crew metabolic rate followed by the RCA bed switch mode and criteria. Other parameters that varied across steady-state test points included the suit pressure and Ventilation Subsystem loop flow rate. In addition to mapping PLSS 1.0 system performance, this collection of nominal steady state test points served the purpose of simulating various EVA modes. For example, the Oxygen Subsystem pressure setpoints were set to values that would be expected for airlock operations prior to depress (1.4 kPa-d, 0.2 psid) or to simulate in-suit decompression sickness treatment (55.2 kPa-d, 8 psid).

Two series of steady-state test points were conducted to characterize PLSS 1.0 performance with respect to anomalous conditions. One investigated the effects of a very low to very high water vapor injection rate into the PGSVS and the other characterized the RCA and Ventilation Subsystem response to potentially adverse, increased RCA vacuum pressures. A group of transient test points was executed to simulate nominal 7-hour EVAs in which the simulated metabolic rate varied with respect to time. Other transient test points simulated contingencies such as suit purges, RCA valve failure, and Thermal Subsystem cooling failure. 


\section{A. Nominal Test Point Operations}

A typical nominal steady-state or 7-hour EVA simulation test point required the adjustment of 16 PLSS 1.0 hardware parameters, which are listed in Table 2. The Oxygen Subsystem was configured by first setting the POR and SOR vacuum chamber pressure and then setting the POR and SOR according to each test point pressure delta criteria. In the vast majority of test points, the POR and SOR chambers were simultaneously evacuated and the SOR $\mathrm{P}_{\Delta}$ was set prior to the POR at $25.5 \mathrm{kPa}$ (3.7 psid) so that it could serve its role as the backup gas supply. The POR was then set to 28.3, 41.4 , or $55.4 \mathrm{kPa}$-delta $(4.1,6,8 \mathrm{psid})$. The POR/SOR chambers were not evacuated for only three test points that simulated airlock operations and had regulator setpoints of $1.4 \mathrm{kPa}$-delta.

Of the Ventilation Subsystem hardware settings, the $\mathrm{CO}_{2}$ injection rate, water vapor injection rate, and $\mathrm{MGC}$ were a function of the simulated crewmember metabolic rate. $\mathrm{CO}_{2}$ injection values in Table 3 were based on Space Shuttle EMU program modeling of crew $\mathrm{CO}_{2}$ production, ${ }^{12}$ whereas water vapor injection rates represented the net of crewmember vapor production minus condensation on the EMU liquid cooling garment. The water vapor injection rates were used in previous RCA testing ${ }^{7}$ and used in PLSS 1.0 testing for the sake of consistency. The metabolic gas consumption rates listed in Table 3 are oxygen consumption rates per Ref. 12, modified to account for the density of nitrogen, the working gas for PLSS 1.0.

Three RCA bed switch modes were tested in PLSS 1.0 with the most common being $\mathrm{CO}_{2}$ partial pressure $\left(\mathrm{P}_{\mathrm{CO} 2}\right)$ dependent and occurring when the PGSVS inlet $\mathrm{P}_{\mathrm{CO} 2}$ reached either 800,467 , or $400 \mathrm{~Pa}(6,3.5,3 \mathrm{~mm} \mathrm{Hg})$. A $\mathrm{P}_{\mathrm{CO} 2}$ RCA bed switch of $800 \mathrm{~Pa}$ was selected pre-test based on previous RCA testing and a goal to maintain instantaneous PGSVS inlet $\mathrm{P}_{\mathrm{CO} 2}$ less than $1013 \mathrm{~Pa}(7.6 \mathrm{~mm} \mathrm{Hg})$. It was
Table 2. List of PLSS 1.0 Hardware Setpoints Required to Execute Nominal Test Point

\begin{tabular}{|c|c|}
\hline Parameter & Range \\
\hline \multicolumn{2}{|l|}{ Oxygen Subsystem } \\
\hline POR chamber pres sure & 0 or $1 \mathrm{~atm}$ \\
\hline $\mathrm{POR} \mathrm{P}_{\Delta}$ & $1.4,25.5$ to $55.4 \mathrm{kPa}$ \\
\hline SOR chamber pres sure & 0 or $1 \mathrm{~atm}$ \\
\hline $\mathrm{SOR} \mathrm{P}_{\Delta}$ & $1.4,25.5$ to $55.4 \mathrm{kPa}$ \\
\hline \multicolumn{2}{|c|}{\begin{tabular}{l|l} 
Ventilation Subsystem & \\
\end{tabular}} \\
\hline Flowrate & 85 to $227 \mathrm{Lpm}$ \\
\hline $\mathrm{CO} 2$ injection & 28 to $280 \mathrm{~g} / \mathrm{hr}$ \\
\hline $\mathrm{H} 2 \mathrm{O}$ injection & 35 to $89 \mathrm{~g} / \mathrm{hr}$ \\
\hline MGC & 18 to $177 \mathrm{~g} / \mathrm{hr}$ \\
\hline Suit leakage & 2.1 to $4.2 \mathrm{~g} / \mathrm{hr}$ \\
\hline RCA bed switch & $\begin{array}{c}400,467,800 \mathrm{P} \mathrm{P}_{\mathrm{CO} 2} \\
(3,3.5,6 \mathrm{~mm} \mathrm{Hg})\end{array}$ \\
\hline \multicolumn{2}{|c|}{\begin{tabular}{l|l} 
Thermal Subsystem & \\
\end{tabular}} \\
\hline Total flow rate & $10,91 \mathrm{~kg} / \mathrm{hr}$ \\
\hline LCGS flow & 3.1 to $90.7 \mathrm{~kg} / \mathrm{hr}$ \\
\hline LCGS DP & 0.5 to $13.6 \mathrm{kPa}$ \\
\hline LCGS heat load & 5 to $827 \mathrm{~W}$ \\
\hline Avionics heat load & $50 \mathrm{~W}$ \\
\hline $\begin{array}{r}\text { SWME outlet water } \\
\text { temperature }\end{array}$ & $10^{\circ} \mathrm{C}$ \\
\hline
\end{tabular}

Table 3. Metabolic Rate Dependent Setpoint Values

\begin{tabular}{|c|c|c|c|c|c|c|c|c|c|c|}
\hline \multicolumn{2}{|c|}{ Metabolic Rate } & \multirow{2}{*}{$\begin{array}{c}\mathrm{CO}_{2} \\
\text { Injection } \\
(\mathrm{g} / \mathrm{hr})\end{array}$} & \multirow{2}{*}{$\begin{array}{c}\mathrm{H}_{2} \mathrm{O} \\
\text { Injection } \\
(\mathrm{g} / \mathrm{hr})\end{array}$} & \multirow[b]{2}{*}{$\begin{array}{l}\text { MGC } \\
(\mathrm{g} / \mathrm{hr})\end{array}$} & \multicolumn{3}{|c|}{ LCGS Heat Load (watts) } & \multicolumn{3}{|c|}{ LCGS Flow Rate $(\mathrm{kg} / \mathrm{hr})$} \\
\hline$(\mathrm{W})$ & (Btu/hr) & & & & Cold & Neutral & Hot & Cold & Neutral & Hot \\
\hline 88 & 300 & 28 & 34.7 & 17.7 & NT & 64 & NT & NT & 3.1 & NT \\
\hline 117 & 400 & 37 & 44.3 & 23.6 & 5 & 87 & 265 & 3.2 & 4.7 & 12.3 \\
\hline 293 & 1000 & 93 & 82.6 & 59.1 & 179 & 237 & 404 & 18.6 & 23.8 & 38.6 \\
\hline 469 & 1600 & 149 & 88.8 & 94.5 & 352 & 409 & 594 & 71.0 & 90.7 & 90.7 \\
\hline 586 & 2000 & 186 & 75.0 & 118.1 & NT & 535 & NT & NT & 90.7 & NT \\
\hline 879 & 3000 & 279 & 75.0 & 177.2 & NT & 827 & NT & NT & 90.7 & NT \\
\hline \multicolumn{5}{|c|}{$\mathrm{NT}=$ Not tested } & \multicolumn{3}{|c|}{$\begin{array}{c}\text { Per EVA thermal } \\
\text { environment }\end{array}$} & \multicolumn{3}{|c|}{$\begin{array}{c}\text { Per EVA thermal } \\
\text { environment }\end{array}$} \\
\hline
\end{tabular}

13

American Institute of Aeronautics and Astronautics 
presumed this $800 \mathrm{~Pa}$ criterion would remain for the duration of the test. However, the PLSS project team became aware of concerns regarding long-term-duration crew exposure to $\mathrm{CO}_{2}{ }^{13}$ and decided to operate in a way that would address these concerns. The new $\mathrm{P}_{\mathrm{CO} 2}$ RCA bed switch criterion was the value that would yield a mean PGSVS inlet $\mathrm{P}_{\mathrm{CO} 2}$ of $293 \mathrm{~Pa}(2.2 \mathrm{~mm} \mathrm{Hg})$ or less for the $469 \mathrm{~W}$ metabolic load cases. This was an iterative process in which several test points were executed with a $467 \mathrm{~Pa} \mathrm{P}_{\mathrm{CO} 2}$ criterion before the final value of $400 \mathrm{~Pa}$ was selected. The other two RCA switch modes were constant RCA bed half-cycle duration and manual bed switching. These modes will be discussed as needed in the results section.

Thermal Subsystem LCGS flow rates and heat loads were also a function of simulated crewmember metabolic rate (see Fig. 12) and obtained from Ref. 14. The water coolant total flow rate was set to $91 \mathrm{~kg} / \mathrm{hr}$ in all but three nominal steady-state and transient test points, while the SWME outlet water temperature target was always $10^{\circ} \mathrm{C}$ $\left(50^{\circ} \mathrm{F}\right)$. LCGS pressure drops were set per test point criteria to approximate EMU Liquid Cooling Ventilation Garment hydraulic performance.

A total of eight 7-hour EVA simulation test points were executed. Three different metabolic rate profiles were used in these tests and are plotted in Fig. 12 The first transient EVA simulation test point executed was TP 67, which had 1-hour duration initial and final $900 \mathrm{~W}$ metabolic rate steps. During the final, 1 hour, $900 \mathrm{~W}$ metabolic rate step, RCA operations caused the Ventilation Subsystem pressure to rise significantly. In the next EVA simulation test point (TP 68), the initial and final steps metabolic rate was reduced to $530 \mathrm{~W}$ to avoid the over-pressurization issues. During the initial and final steps of this second profile, the Thermal Subsystem was still operated at a $900 \mathrm{~W}$ metabolic rate to continue assessment of the SWME high heat rejection performance. A third profile that had a maximum metabolic rate of $700 \mathrm{~W}$ was

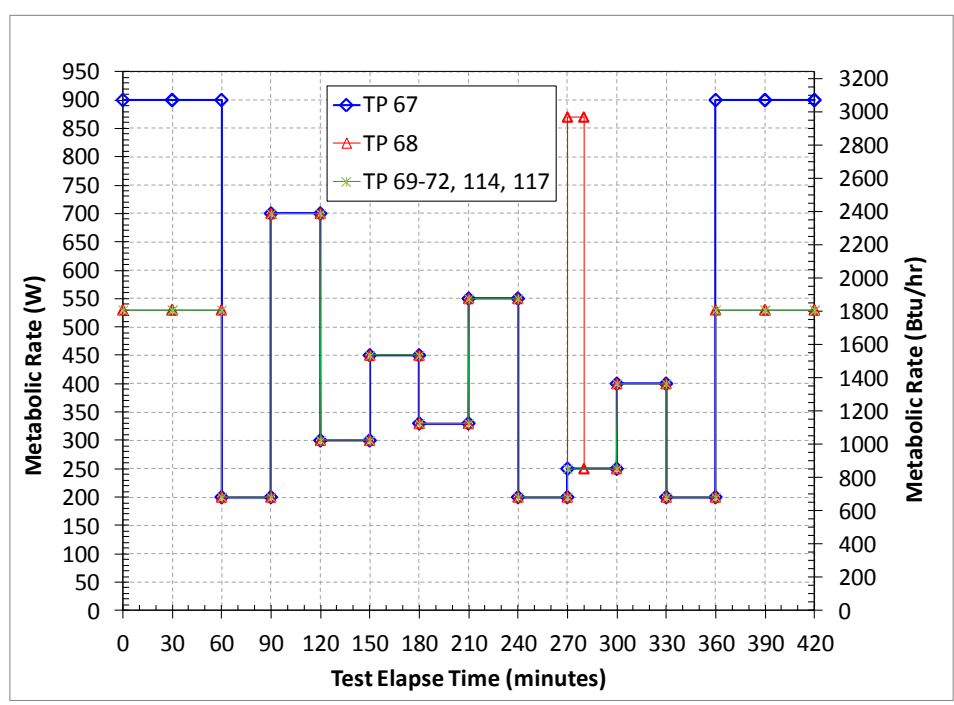

Figure 12. Nominal 7-hour EVA operations test point simulated metabolic rate profile.

then used for the remaining EVA simulation test points. As with the TP 68 profile, the Thermal Subsystem was operated at a $900 \mathrm{~W}$ metabolic rate during the initial and final hour-long steps. Finally, test point operations for the contingency transient test points such as purge operations or POA to SOA transition will be discussed in the results section as needed.

\section{Results}

PLSS 1.0 testing generated a very large database of test results. It was decided to present detailed test results for a few select topics rather than try to summarize all test data. Fortunately, other papers submitted for International Conference on Environmental Systems 2012 publication present PLSS 1.0 test results. In particular, the RCA performance characterization paper details the RCA response to extreme water vapor humidity levels, degraded RCA vacuum pressures, and temporary failure of the RCA valve. In addition, the SWME paper discusses test results from an ad hoc degassing investigation performed during PLSS 1.0 testing. Results from steady-state test points are presented first and include a detailed look PLSS performance during an arbitrarily selected steady-state test point and parametric analyses with respect to simulated metabolic rates and constant RCA half-cycle times. Presented transient test results include nominal EVA simulation and purge flow simulations.

\section{A. Results from Steady-State Test Points}

Steady-state test points accounted for 147 of the total PLSS 1.0 test points executed. Because real-time plotting of transient test data was limited, an initial, quick-look analysis of these test points generated three graphs per test point to verify steady state was attained. Two of the graphs plotted Ventilation and Thermal Subsystem measurements to confirm test setpoints (Table 2) were properly achieved. The third graph plotted Ventilation 
Subsystem $\mathrm{CO}_{2}$ and $\mathrm{H}_{2} \mathrm{O}$ measurements to verify that these gas constituents reached cyclical steady state. Only one test point was found to have been cut short prior to achieving steady state. This initial assessment also served as the first step in identifying notable test results.

\section{An In-Depth Look at the Steady-State Test Point 5R800}

Steady-state test point 5R800 was arbitrarily selected to illustrate the PLSS 1.0 performance from a system-level perspective. TP 5R800 was executed during the middle of the test program and was a repeat of the original test point. Figure 13 summarizes PLSS 1.0 performance by overlaying TP 5R800 test results on the PLSS 1.0 functional schematic. Most of the Oxygen and Ventilation Subsystems measurements were mean values calculated over the 60minute cyclical steady-state period while the Thermal Subsystem measurements were instantaneous values at a time in which the Thermal Subsystem was at steady state. POV and SOV gas pressures measurements taken at the start and end of the ventilation subsystem (VS) cyclical steady-state period are denoted "i" for initial and "f" for final.

The TP 5R800 steady-state period lasted about 60 minutes in which the Oxygen Subsystem supplied nitrogen at a mean rate of $68.2 \mathrm{~g} / \mathrm{hr}$ while maintaining the VS at a mean pressure of $28.5 \mathrm{kPa}$-delta. Because the Oxygen Subsystem delta pressure transducer reference was at vacuum, the Oxygen Subsystem supply mean pressure represents the VS absolute pressure assuming the pressure drop induced by the $68.2 \mathrm{~g} / \mathrm{hr}$ nitrogen flow is negligible. A quick glance at the PGSVS inlet absolute pressure transducer mean measurement shows a $1.4 \%$ difference between it and the Oxygen Subsystem supply pressure, thus verifying good agreement. About $12 \%(8.2 \mathrm{~g} / \mathrm{hr})$ of the Oxygen Subsystem nitrogen flow was attributable to the SOA even though the SOA was set to a lower pressure $(25.5 \mathrm{kPa}, 3.7 \mathrm{psid})$ and therefore closed. This small SOR flow is referred to as the regulator lock-up leakage and was within expected values for a regulator subjected to uncontrolled handling processes.

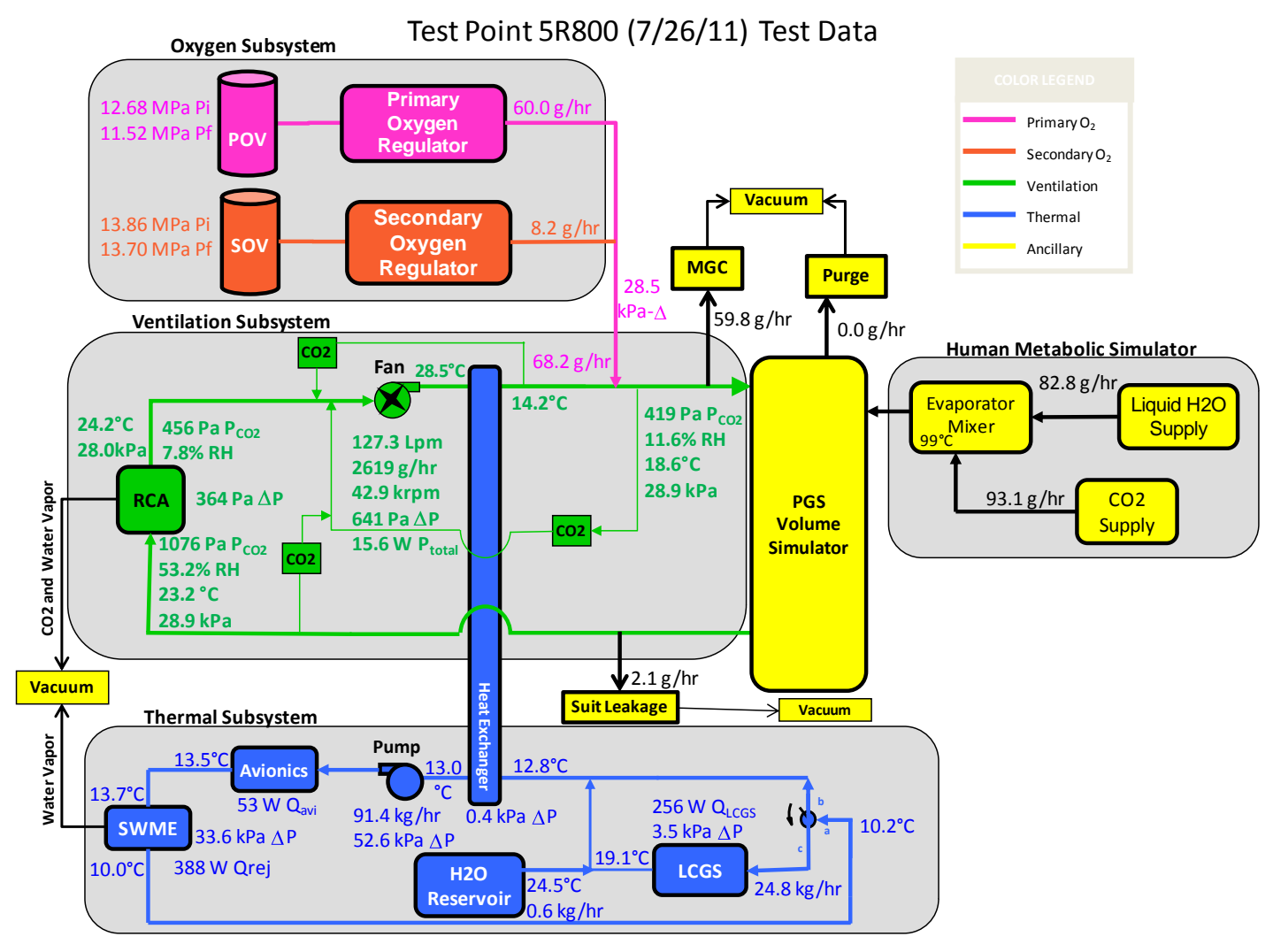

Figure 13. Summary of TP 5R800 test results - a $293 \mathrm{~W}$ metabolic rate, $28.3 \mathrm{kPa}$ pressure, 127.4 Lpm flow rate, $800 \mathrm{~Pa}$ RCA switch $(1000 \mathrm{Btu} / \mathrm{hr}, 4.1 \mathrm{psia}, 4.5 \mathrm{acfm}, 6 \mathrm{~mm} \mathrm{Hg})$, neutral thermal environment test point. 
Comparing VS mean measurements of 127.3 Lpm VS loop flow, $59.8 \mathrm{~g} / \mathrm{hr}$ MGC flow, $2.1 \mathrm{~g} / \mathrm{hr}$ SL flow, 93.1 $\mathrm{g} / \mathrm{hr} \mathrm{CO}$ injection, and $82.8 \mathrm{~g} / \mathrm{hr} \mathrm{H}_{2} \mathrm{O}$ injection to test point setpoints of $127.4 \mathrm{Lpm}, 59.1 \mathrm{~g} / \mathrm{hr}, 2.1 \mathrm{~g} / \mathrm{hr}, 93.0 \mathrm{~g} / \mathrm{hr}$, and $82.6 \mathrm{~g} / \mathrm{hr}$ confirms the test point VS parameters were established well within acceptable tolerances. Given these setpoints, the RCA responded such that its inlet and outlet mean $\mathrm{P}_{\mathrm{CO} 2}$ converged to 1076 and $456 \mathrm{~Pa}$, respectively, and $\mathrm{H}_{2} \mathrm{O}$ relative humidities (RHs) to 53.2 and 7.8\%. The PGSVS inlet mean $\mathrm{P}_{\mathrm{CO} 2}$ of $456 \mathrm{~Pa}(3.4 \mathrm{~mm} \mathrm{Hg})$ exceeded the $293 \mathrm{~Pa}$ goal and was expected since this test point was a repeat. The gas stream supplied to the crew (PGSVS inlet) is obviously very dry and, for the sake of a comparison, would fall in the Constellation Program suited crew requirement's 2-hour exposure limit of 5\% to $15 \% \mathrm{RH}^{15}$ The low humidities were surprising at first until it was discovered the RCA was mistakenly plumbed in the "single-ended vacuum-inlet" configuration, the most efficient water adsorption mode possible. Finally, the RCA inlet and outlet measurements yield calculated $\mathrm{RCA} \mathrm{CO}_{2}$ and $\mathrm{H}_{2} \mathrm{O}$ mean adsorption rates of 99.0 and $79.6 \mathrm{~g} / \mathrm{hr}, 6.3 \%$ above and $3.9 \%$ below respective HMS injection rates.

As the VS gas stream traveled from the RCA to the PGSVS, it cooled down via the gas/water heat exchanger and was diluted by the Oxygen Subsystem nitrogen injection. The former resulted in a higher PGSVS inlet mean RH (11.6\%) in spite of the dilution. The dilution was readily apparent in the lower PGSVS inlet mean $\mathrm{P}_{\mathrm{CO} 2}$ of $419 \mathrm{~Pa}$ $(3.14 \mathrm{~mm} \mathrm{Hg})$. Note the gas stream temperatures increased $4.4^{\circ} \mathrm{C}\left(39.9^{\circ} \mathrm{F}\right)$ from the heat exchanger outlet to the PGSVS inlet and then a further $4.6^{\circ} \mathrm{C}\left(40.3^{\circ} \mathrm{F}\right)$ to the RCA inlet. These temperature increases were expected due to the numerous invasive instruments, un-insulated PGSVS tank, and injection of high-temperature $\mathrm{CO}_{2}$ and $\mathrm{H}_{2} \mathrm{O}$.

A fan speed of $42.9 \mathrm{krpm}$ was required to generate necessary VS loop flow and resulted in a total power consumption of $15.6 \mathrm{~W}$. It is estimated the fan total power was split 33/67\% (5.2/10.4 W) between the fan motor and COTS controller per Hamilton Sundstrand test data. ${ }^{5}$ Measurements about the fan yield an estimated $1.4 \mathrm{~W}$ aerodynamic power imparted to the gas stream and the transference of $3.3 \mathrm{~W}$ of heat to the gas stream. In theory, the fan motor power should be balanced by imparted aerodynamic power and heat acquisition if the fan is perfectly insulated. The $4.7 \mathrm{~W}$ sum of aerodynamic power and acquired heat is $90 \%$ of the estimated $5.2 \mathrm{~W}$ fan power and indicates a better-than-expected performance of the COTS insulation applied to the fan and adjacent VS components.

Thermal Subsystem parameters summarized in Fig. 13 indicate nominal performance. The SWME outlet temperature was maintained at $10^{\circ} \mathrm{C}\left(50^{\circ} \mathrm{F}\right)$ and the $91.4 \mathrm{~kg} / \mathrm{hr}$ pump and $24.8 \mathrm{~kg} / \mathrm{hr}$ LCGS flows were well within tolerances. The $256 \mathrm{~W}$ LCGS heat load and $53 \mathrm{~W}$ avionics heat load were also within tolerances $( \pm 10 \%)$. Comparing the combined LCGS and avionics heat load of $309 \mathrm{~W}$ to the $388 \mathrm{~W}$ SWME heat rejection suggests the Thermal Subsystem loop is acquiring some environmental heat. This can be seen by the water temperature rise from the avionics outlet to the SWME inlet. Another source of energy is the relatively warm water flow from the reservoir.

\section{Extending the In-Depth Look at the Steady-State Test Point 5 R800 via Transient Plots}

Figure 14 plots a combination of Oxygen Subsystem and VS measurements to illustrate cyclical steady-state gas dynamics during TP 5R800. Immediately notable are the gas pressure and VS loop flow rate spikes that occur when the RCA beds are switched. Pressure spikes occurred because the $689.5 \mathrm{kPa}$ (100 psi) compressed nitrogen used to drive the RCA spool valve was vented into the VS after each RCA bed switch. The POR responded by closing off completely and then reopened once pressures sensed by the regulator became too low. After this adjustment period, steady-state pressures are maintained by the POR with POR nitrogen injections balancing the VS outflows. While the pressure spikes could be problematic for the crew member, a detailed assessment from the human factors perspective was not undertaken due to future plans to replace the spool valve with a better valve design. 


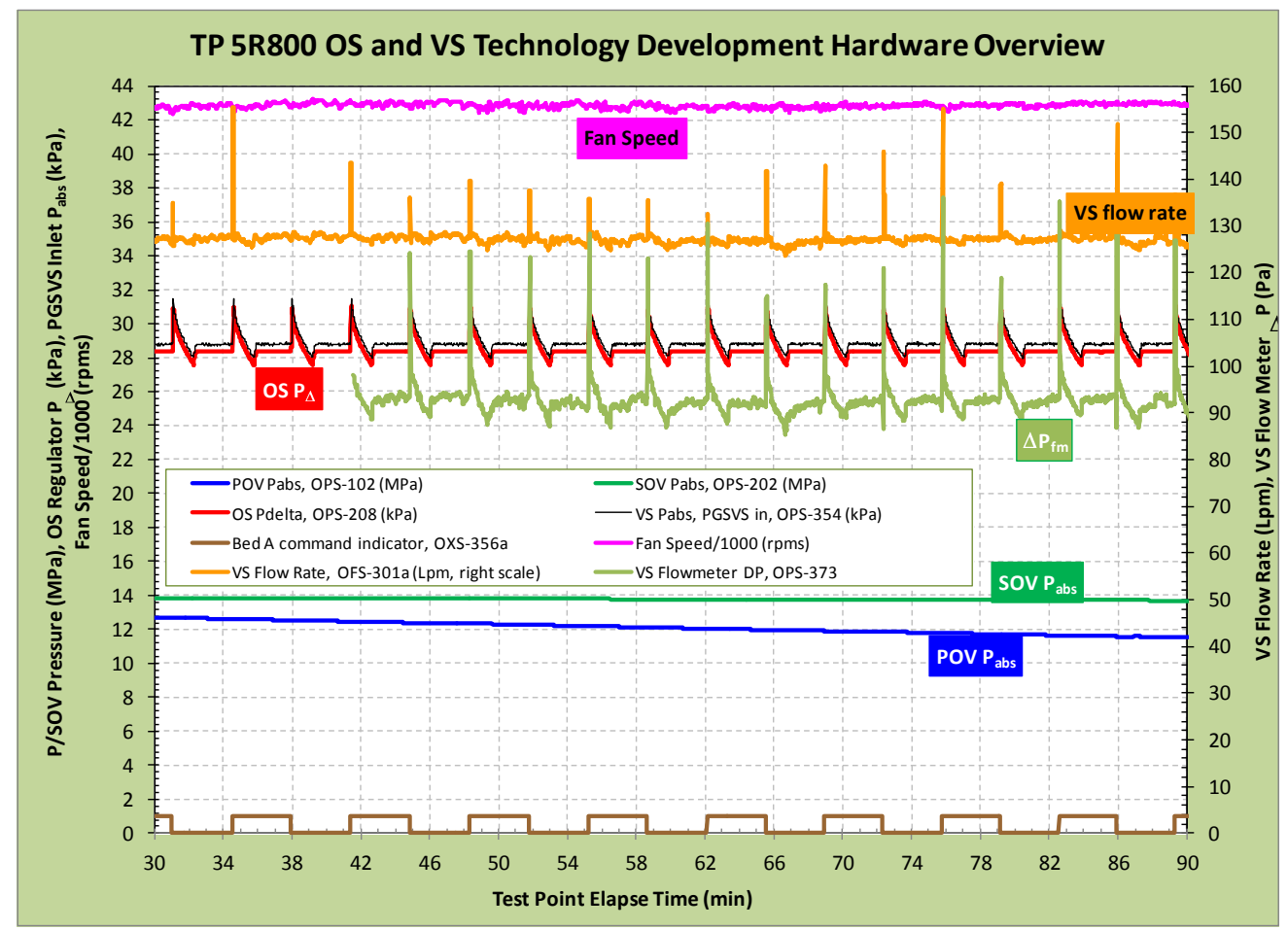

Figure 14. Oxygen Subsystem and VS operations during TP 5R800.

The POR interstage pressures plotted in Fig. 15 further illustrate the described POR operations showing that the interstage pressure rose in response to suddenly increased VS pressures indicating the closure of the POR second stage. A sudden drop in POR interstage pressure occurred when the POR second stage opened up in response to low VS pressures. Finally, the POR interstage gauge pressure reached a steady value of $1.252 \mathrm{MPa}-\mathrm{g}$ during the steady VS pressure regime prior to the next RCA bed switch. 


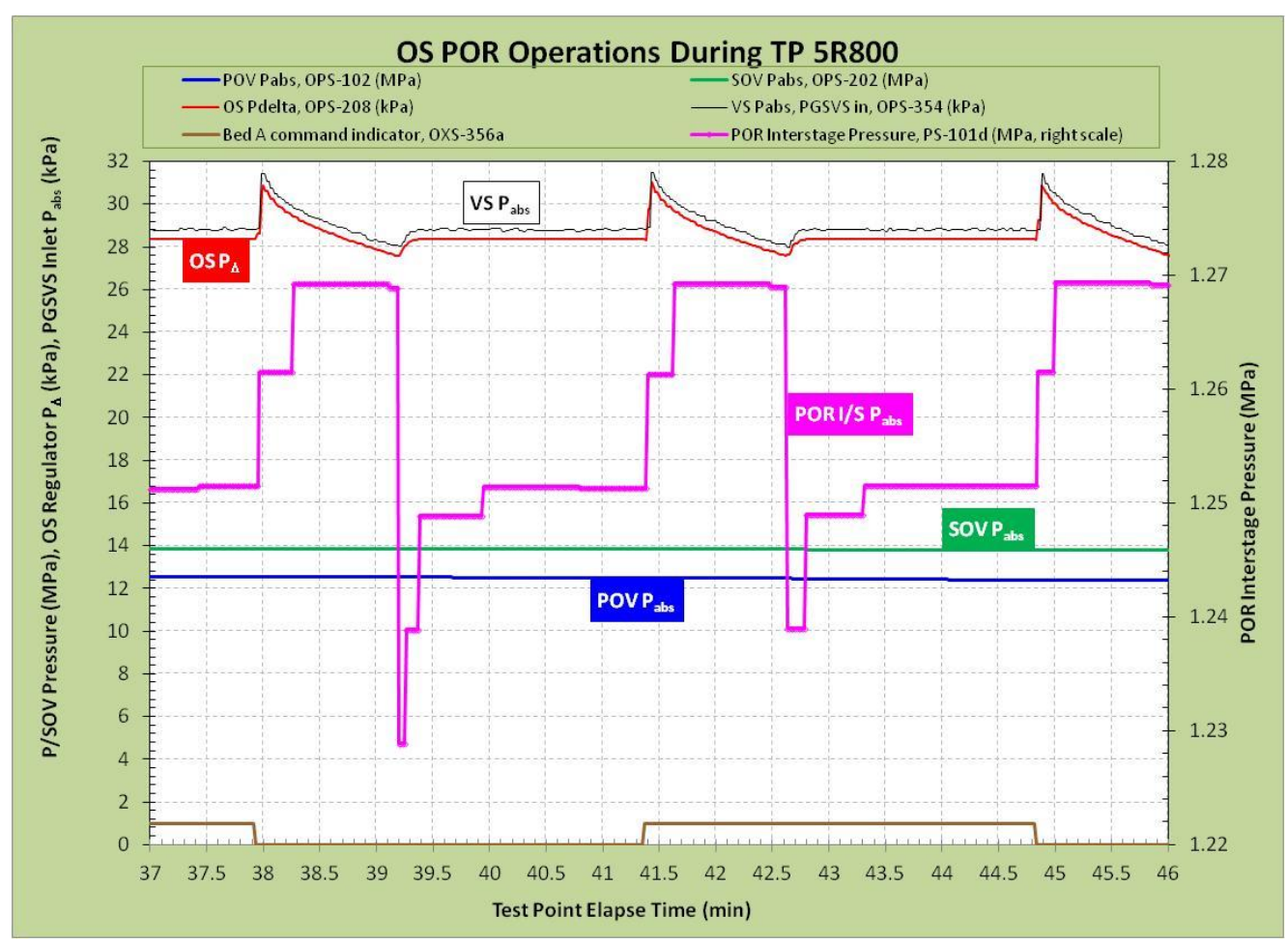

Figure 15. A closer look at Oxygen Subsystem POR operations during TP 5R800.

Flow rate spikes in Fig. 14 are symptomatic of the pressure wave traveling through the VS loop, as can be seen by comparing the VS flow meter pressure drop spikes to the relatively constant fan speeds. The VS flow meter volumetric flow rate is a calculated value proportional to the square root of the flow meter $\Delta \mathrm{P}$ divided by the flow meter inlet gas absolute pressure, $\mathrm{V} \operatorname{dot}=\mathrm{V} \operatorname{dot}\left(\left(\Delta \mathrm{P} / \mathrm{P}_{\mathrm{abs}}\right)^{1 / 2}\right)$. Consequently, the volumetric flow rate upward spikes resulted from flow meter $\Delta \mathrm{P}$ spikes that were larger than the gas absolute pressure spikes and confirm the presence of a pressure wave perturbation traveling through the VS loop toward the PGSVS.

All TP 5R800 $\mathrm{CO}_{2}$ and $\mathrm{H}_{2} \mathrm{O}$ measurements are plotted in Fig. 16, showing cyclical steady-state was reached with measurements repeating their respective patterns. The RCA bed switches consistently occurred when the PGSVS inlet $\mathrm{P}_{\mathrm{CO} 2}$ reached $800 \mathrm{~Pa}(6 \mathrm{~mm} \mathrm{Hg})$, resulting in bed half-cycle times averaging 3.44 and 3.45 minutes for bed A and $\mathrm{B}$, respectively. The comparison of the RCA exit and PGSVS inlet $\mathrm{P}_{\mathrm{CO} 2}$ and how it confirms the POR actions is also notable in Fig. 16. The two $\mathrm{CO}_{2}$ partial-pressure curves only trended together at the beginning of a half cycle because the POR is closed. About 1 minute 20 seconds later, on average, the PGSVS inlet $\mathrm{P}_{\mathrm{CO} 2}$ dips momentarily when the POR initially opens. Continuous nitrogen injection results in a $100 \mathrm{~Pa}$ spread between the two $\mathrm{P}_{\mathrm{CO} 2}$ curves at the half-cycle end. Two other features of Fig. 16 worth noting are the bed A to bed B RH asymmetries and RCA inlet $\mathrm{CO}_{2}$ and $\mathrm{RH}$ downward spikes at the beginning of each half cycle. The latter indicates an RCA valve-induced pressure wave traveling toward the PGSVS against the nominal gas stream flow; the former is marked by the different peak instantaneous RHs for each half cycle in Fig. 16. 


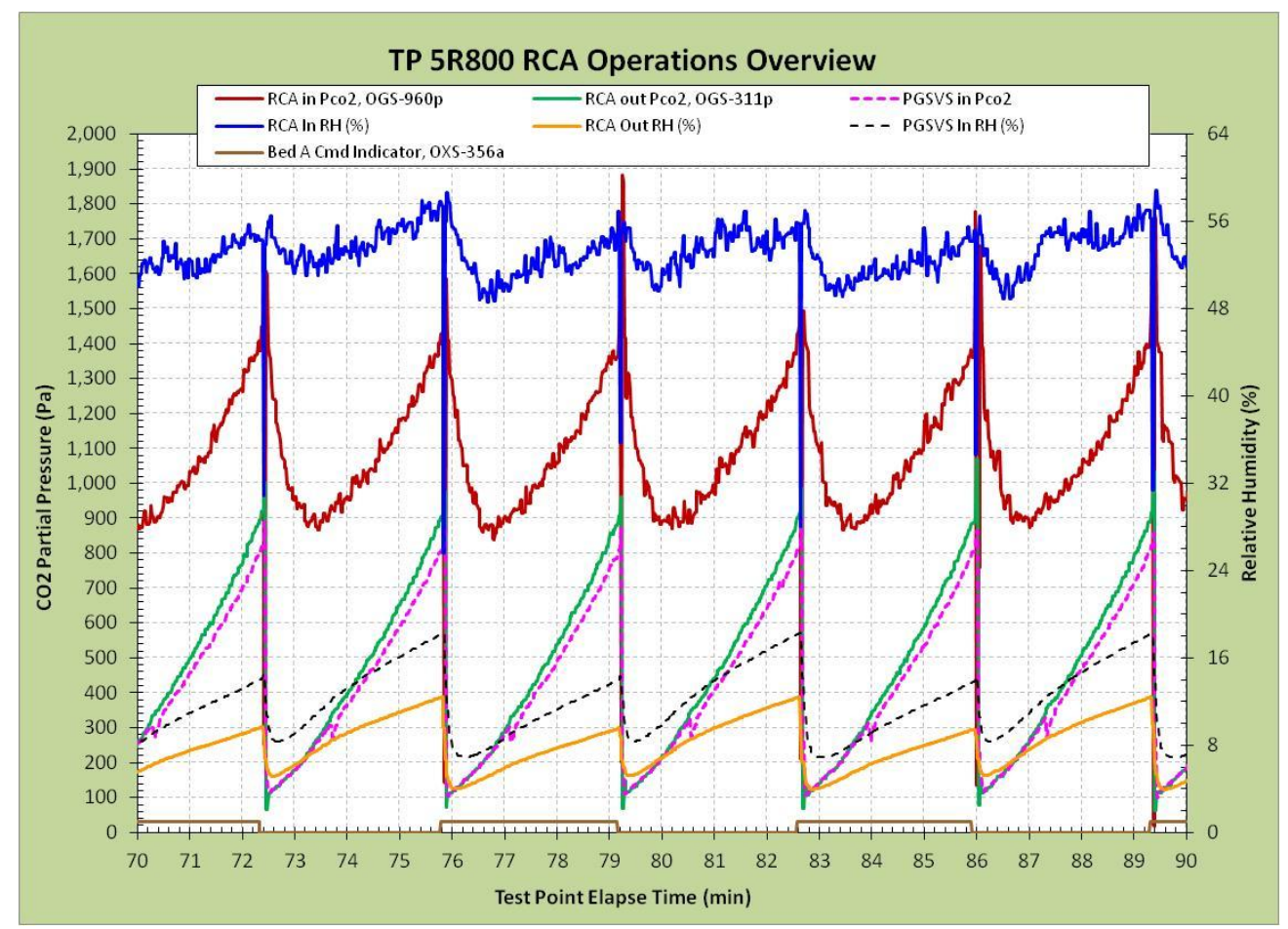

Figure 16. TP 5R800 VS gas constituent test data at the RCA inlet, RCA outlet, and PGSVS inlet.

Test point 5R800 Thermal Subsystem transient test data in Fig. 17 illustrates typical steady-state Thermal Subsystem performance in which most measurements are very steady and only minor adjustments to heater power or the SWME BPV were required. BPV linear potentiometer voltage measurements, plotted in Fig. 17, correspond to valve throat area with a completely open valve resulting in potentiometer measurement of approximately $4400 \mathrm{mV}$. TP 5R800 BPV voltage measurements ranged from 690 to $745 \mathrm{mV}$, thus indicating that valve adjustments were $1 \%$ or less of the fully open BPV throat area during this test point phase. 


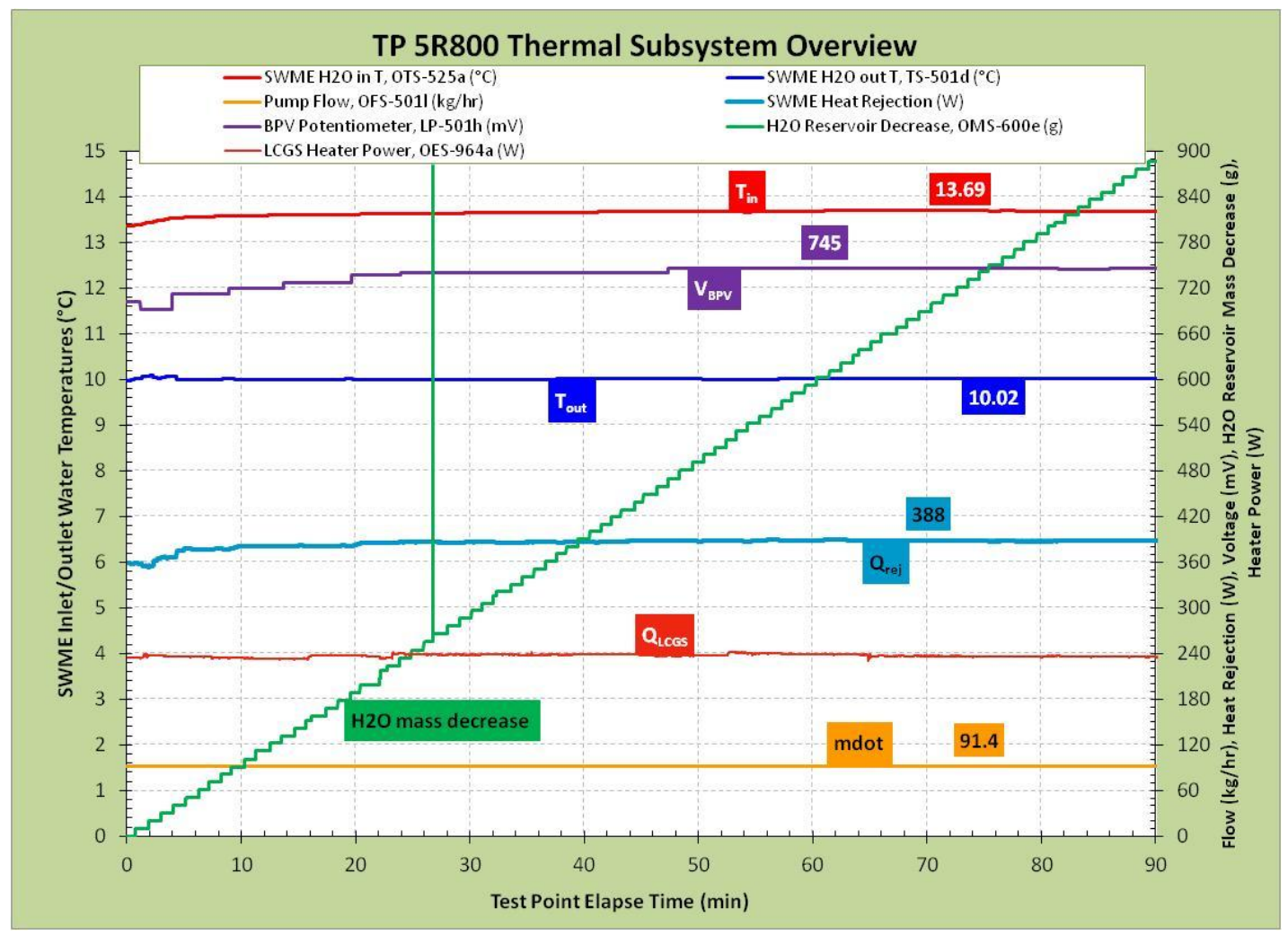

Figure 17. Thermal Subsystem test data during TP 5R800.

The water reservoir mass measurements, while stair-stepped, were linear with respect to time, thereby confirming that the SWME was evaporating water and, therefore, rejecting heat at a steady-state rate. From a test elapse time of 30 to 90 minutes the reservoir supplied $600 \mathrm{~g}$ of make-up water. The $10 \mathrm{~g} / \mathrm{min}$ make-up water rate yields a $412 \mathrm{~W}$ average SWME heat rejection rate assuming a $2473 \mathrm{~kJ} / \mathrm{kg}$ water latent heat of vaporization. Figure 17 plots the SWME heat rejection calculated from SWME inlet/outlet temperatures and water flow rate measurements showing this value was $388 \mathrm{~W}$ during the same time period. The ratio of the water evaporated per SWME heat rejection calculations to the measured water consumption is a mass balance measure called the utilization and was 0.94 in this case.

\section{PLSS 1.0 Test Results Versus Metabolic Rates}

The parametric analysis with respect to metabolic rates is presented first because varying metabolic rates affected the greatest number of Ventilation and Thermal Subsystem hardware setpoints and, more importantly, represents a fundamental function of crew activity level. The two key concerns that arise from the crewmember perspective are whether the PLSS will provide an acceptable gas stream and maintain proper thermal control. A limited data set is used for this analysis and consists of $127.4 \mathrm{Lpm}$ Ventilation Subsystem loop flow rates test points.

Mean $\mathrm{P}_{\mathrm{CO} 2}$ and RH at the PGSVS inlet for test points limited to RCA bed switching at instantaneous PGSVS inlet $\mathrm{P}_{\mathrm{CO} 2}$ levels of $400 \mathrm{~Pa}(3 \mathrm{~mm} \mathrm{Hg})$ are presented in Fig. 18. Immediately notable, and not surprising, is the rising mean $\mathrm{P}_{\mathrm{CO} 2}$ with respect to increasing metabolic rates since $\mathrm{CO}_{2}$ injection rates are proportional to metabolic rates. The PLSS responded to increasing metabolic rates and $\mathrm{CO}_{2}$ injection rates by cycling the RCA faster as shown in Fig. 19. This response matches expectations based on independent RCA testing and modeling. Test results also indicate Ventilation Subsystem absolute pressure has minimal impact on RCA performance; another expected result due to the fact the RCA works on partial pressure principles when the vacuum levels are adequate. Mean PGSVS RHs decreased with respect to increasing metabolic rates due to the faster RCA cycling and because the water vapor injection rates change minimally at metabolic rates greater than $293 \mathrm{~W}$ (see Table 3). 


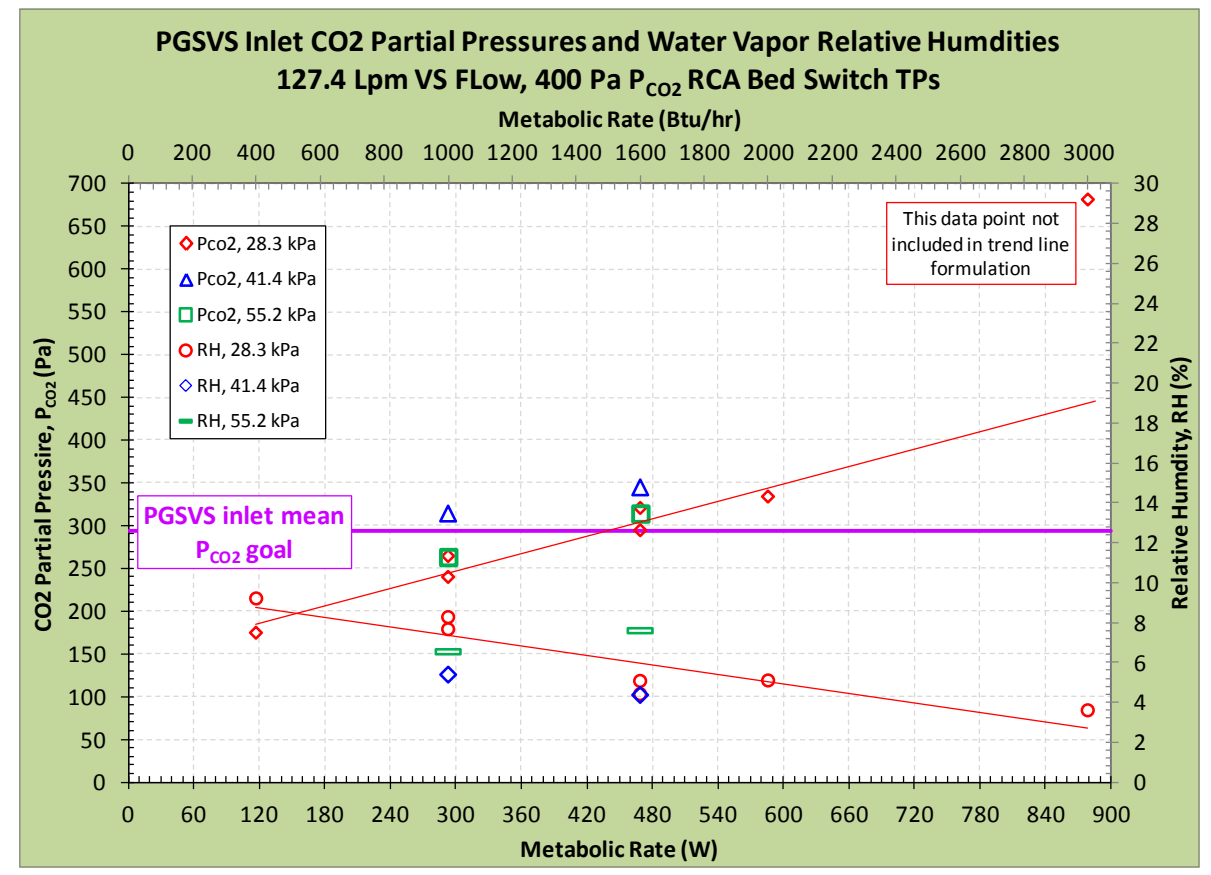

Figure 18. Mean PGSVS inlet $\mathrm{CO}_{2}$ partial pressures and RHs for the $400 \mathrm{~Pa}$ $P_{\mathrm{CO} 2}$ RCA bed switch, 127.4 Lpm test points.

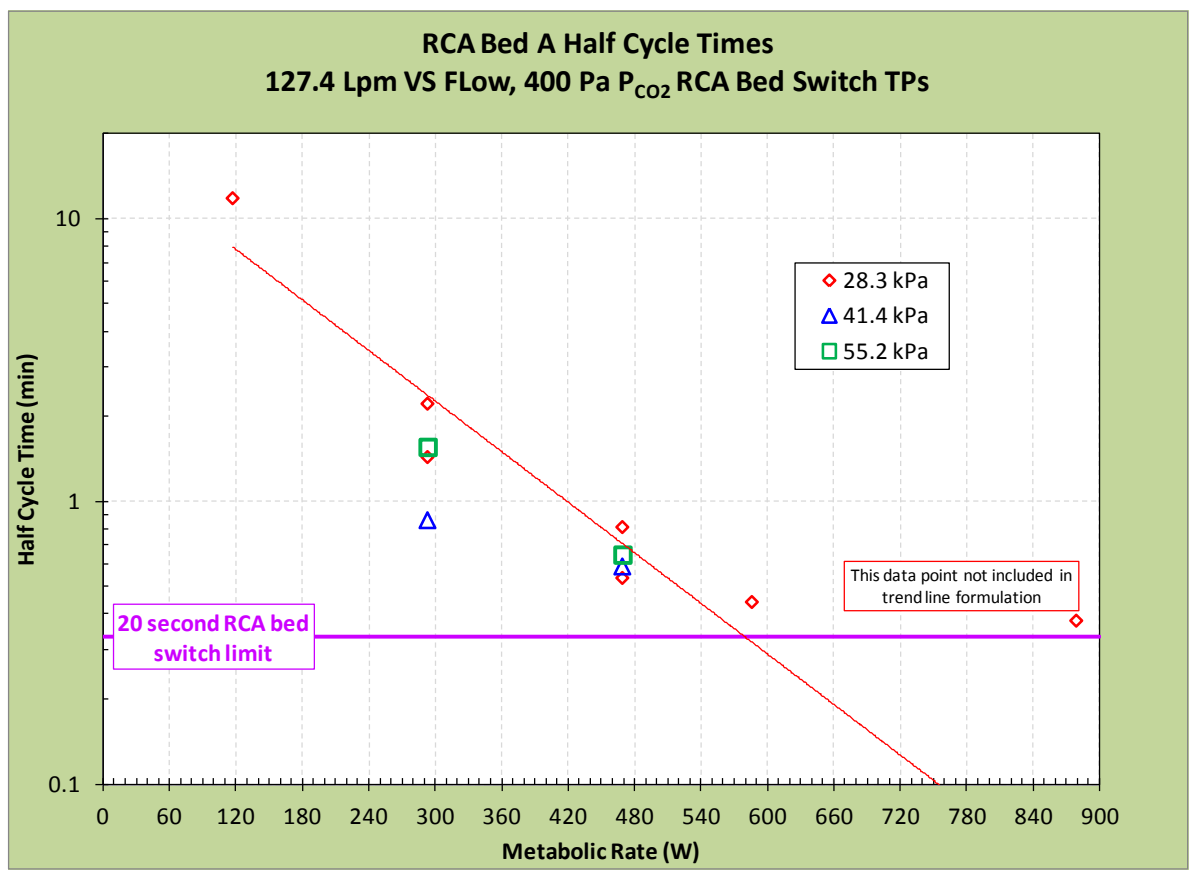

Figure 19. RCA half cycle times for the $400 \mathrm{~Pa} \mathbf{P}_{\mathrm{CO} 2}$ RCA bed switch, 127.4 Lpm test points. 


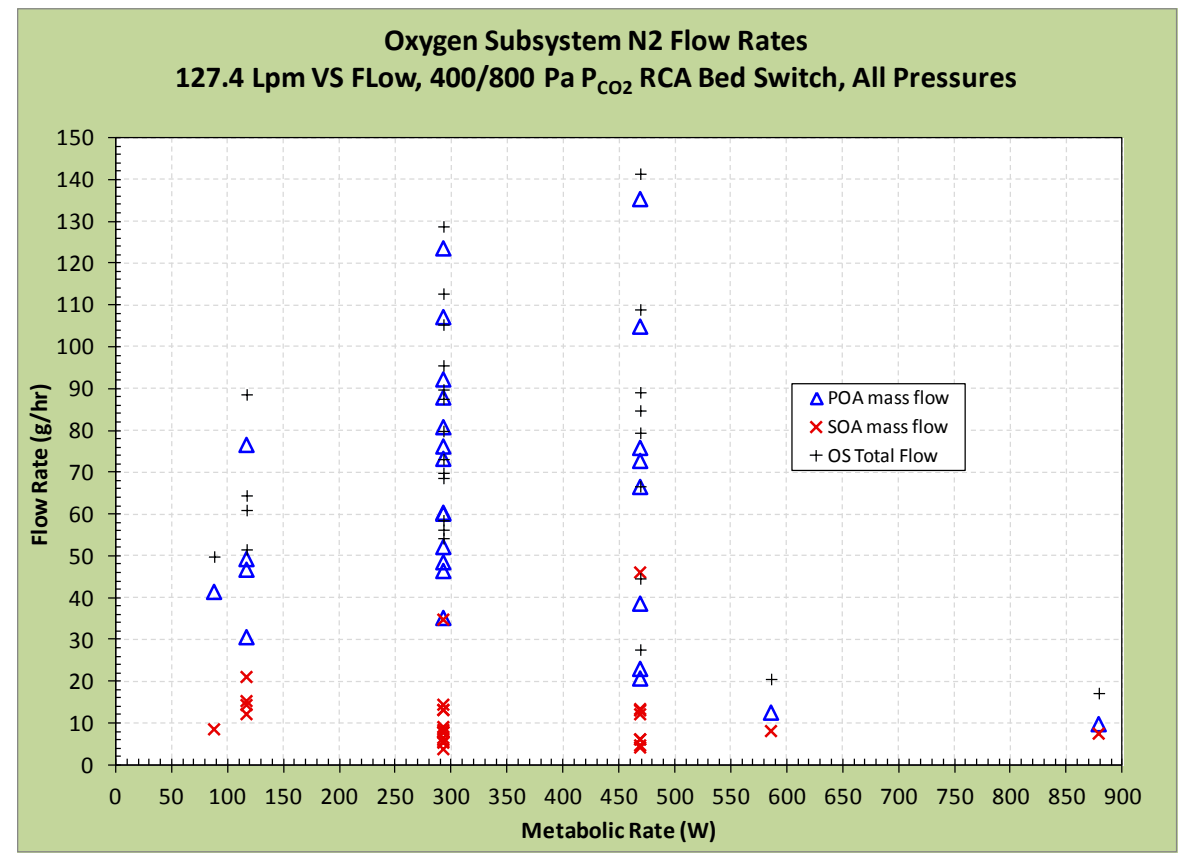

Figure 20. Oxygen Subsystem POA, SOA, and total gas supply flow rates.

An important result illustrated by Fig. 18 and Fig. 19 is the scatter about the 293 and 469 W (1000 and 1600 $\mathrm{Btu} / \mathrm{hr}$ ) metabolic rates. Recall the latter value was used to determine the RCA bed switch criterion of $400 \mathrm{~Pa} \mathrm{P}_{\mathrm{CO} 2}$. Test results show that only one $469 \mathrm{~W}$ metabolic rate test point saw the PGSVS inlet mean $\mathrm{P}_{\mathrm{CO} 2}$ achieving the 293 Pa mean target. In the other test points, the PGSVS inlet mean $\mathrm{P}_{\mathrm{CO} 2}$ ranged from 314 to $345 \mathrm{~Pa}, 7 \%$ to $18 \%$ above the $293 \mathrm{~Pa}$ target. The significance of this scatter is that the RCA bed switch criterion might have to be lower to account for scatter and that would increase demands on the PLSS due to increased ullage losses and RCA valve cycling. Scatter was even greater in the $293 \mathrm{~W}$ metabolic rate test points with PGSVS inlet mean $\mathrm{P}_{\mathrm{CO} 2}$ ranging from 240 to $314 \mathrm{~Pa}$. Scatter is also evident in the RCA bed half-cycle times with a range of 0.9 to 2.2 minutes for the 293 $\mathrm{W}$ metabolic rate test points and 0.54 and 0.82 minutes for the $469 \mathrm{~W}$ test points. The cause of this scatter is not fully understood and should be pursued further. 


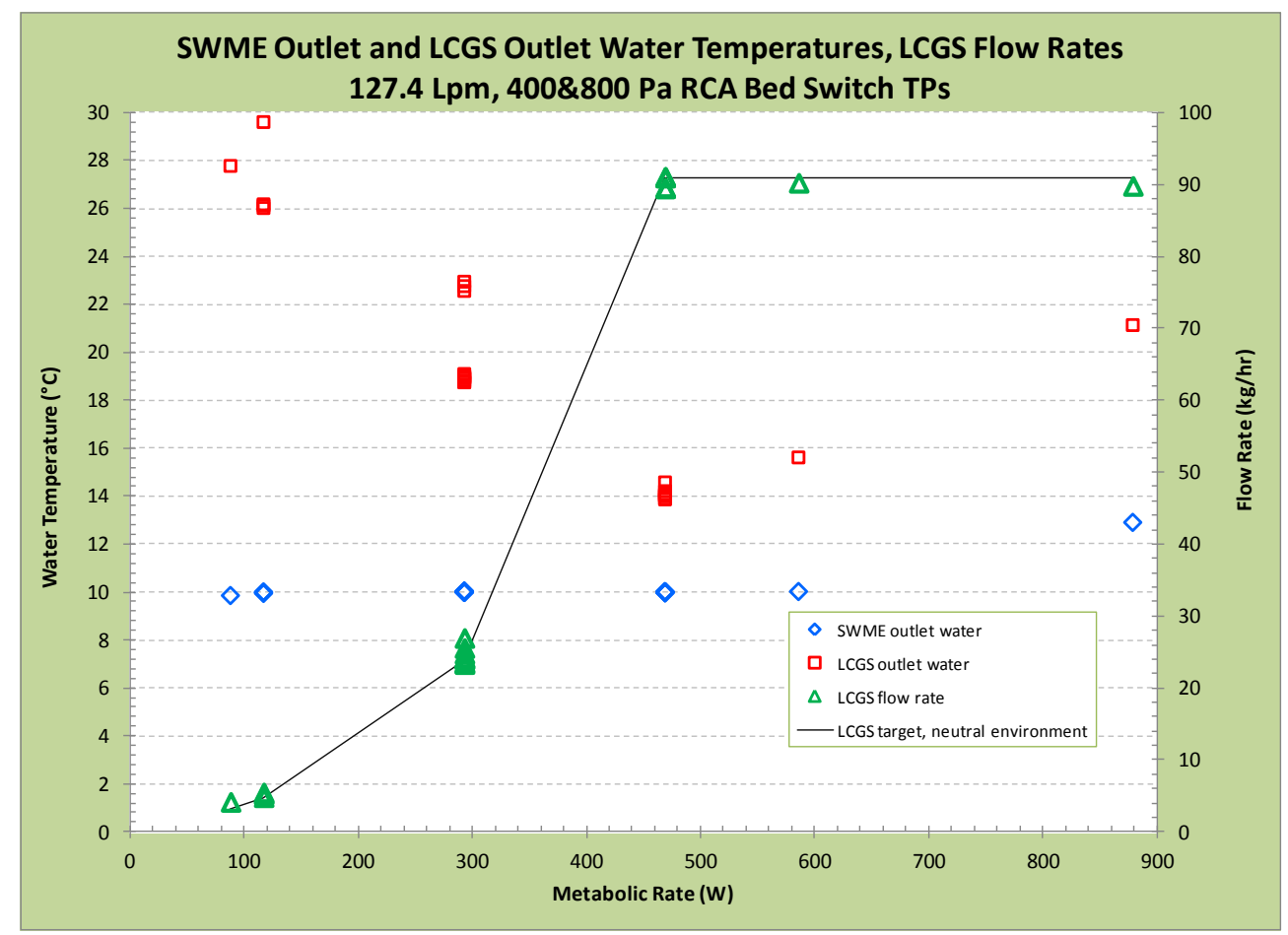

Figure 21. Summary of Thermal Subsystem response to varying metabolic rates.

Mean PGSVS inlet $\mathrm{P}_{\mathrm{CO} 2}$ and RCA half-cycle times from the two very high metabolic rate test points show that the $586 \mathrm{~W}(2000 \mathrm{Btu} / \mathrm{hr})$ metabolic rate results trended with the lower metabolic rate test results, whereas the $879 \mathrm{~W}$ $\left(3000 \mathrm{Btu} / \mathrm{hr}\right.$ ) metabolic rate test results did not. In the $879 \mathrm{~W}$ test point, the mean PGSVS inlet $\mathrm{P}_{\mathrm{CO} 2}$ reached a maximum of $681 \mathrm{~Pa}(5.1 \mathrm{~mm} \mathrm{Hg})$; in part due to the 20-second RCA half-cycle time limit programmed into the DACS.

Oxygen Subsystem POA, SOA, and total nitrogen supply flow rates plotted in Fig. 20 proved interesting for several reasons. First is the large scatter exhibited by the test data, as illustrated by the total nitrogen flow rates ranging from 27.6 to $141.4 \mathrm{~g} / \mathrm{hr}$ for the $469 \mathrm{~W}$ metabolic rate test points. Another interesting result is the weak correlation between metabolic rates and total nitrogen flow rates. From metabolic rates ranging from 88 to $469 \mathrm{~W}$, the maximum POA and total flow rates trended upward whereas the minimum total flow rates trended downward. The upward trend was expected due to increasing metabolic gas consumption and RCA ullage losses whereas the minima downward trend proved surprising. Some ideas about the cause of this divergence exist, yet an analytical investigation would involve calculating nitrogen mass balances and should be pursued when resources permit. The very low 586 and $879 \mathrm{~W}$ test point flow rates are believed to be caused by the fast RCA cycling venting significant amounts of RCA valve motive nitrogen being into the Ventilation Subsystem. The SOA lock-up leakage ranged from 3.7 to $46 \mathrm{~g} / \mathrm{hr}$ while averaging $12 \mathrm{~g} / \mathrm{hr}$. Finally, even though not shown, the 400 and $800 \mathrm{~Pa}$ RCA bed switch test point data trend similarly and both support the general observations.

The Thermal Subsystem response to varying metabolic rates is summarized in Fig. 21. The SWME was able to produced $10^{\circ} \mathrm{C}\left(50^{\circ} \mathrm{F}\right)$ outlet water for all metabolic rates except $879 \mathrm{~W}$. LCGS flow rates were successfully adjusted according to metabolic rates, resulting in LCGS outlet temperatures trending as expected. During low metabolic rate activity, the crewmember typically desire warmer water so that they do not become chilled. As activity levels increase, the desire for greater cooling manifests itself in higher cooling garment flow rates and lower coolant temperatures.

\section{Constant Rapid Cycle Amine Bed Half-Cycle-Duration Test Results}

Currently, one plan under consideration to mitigate a $\mathrm{CO}_{2}$ sensor failure is to switch RCA beds at constant intervals. This test series explores the feasibility of constant RCA bed half-cycle times by mapping out $\mathrm{CO}_{2}$ levels as a function of half-cycle times ranging from 23 to 60 seconds, metabolic rates ranging from 117 to $703 \mathrm{~W}$ (400 to 
$2400 \mathrm{Btu} / \mathrm{hr}$ ), and at 28.3 and $41.4 \mathrm{kPa}$ (4.1 and 6 psia) VS gas stream pressures. Results plotted in Fig. 22 proved to be illuminating for performing as expected as well as for the surprises. The $703 \mathrm{~W}$ test series provides an example of what was expected, showing PGSVS inlet mean $\mathrm{P}_{\mathrm{CO} 2}$ decreased significantly as half-cycle times were reduced. Sixty-second half-cycle time $703 \mathrm{~W}$ mean $\mathrm{P}_{\mathrm{CO} 2}$ ranged from 940 to $985 \mathrm{~Pa}(7.1$ to $7.4 \mathrm{~mm} \mathrm{Hg}$ ) whereas both 25 second half-cycle time mean $\mathrm{P}_{\mathrm{CO} 2}$ were $374 \mathrm{~Pa}(2.8 \mathrm{~mm} \mathrm{Hg})$, an average decrease of $61 \%$. The $374 \mathrm{~Pa} \mathrm{P}_{\mathrm{CO} 2}$ minimum in the $703 \mathrm{~W}$ test series, while not below the $293 \mathrm{~Pa}$ goal, was close to the $382 \mathrm{~Pa}_{\mathrm{CO} 2}$ extrapolated from the $400 \mathrm{~Pa}$ RCA bed switch, metabolic rate-based test results in Fig. 18.

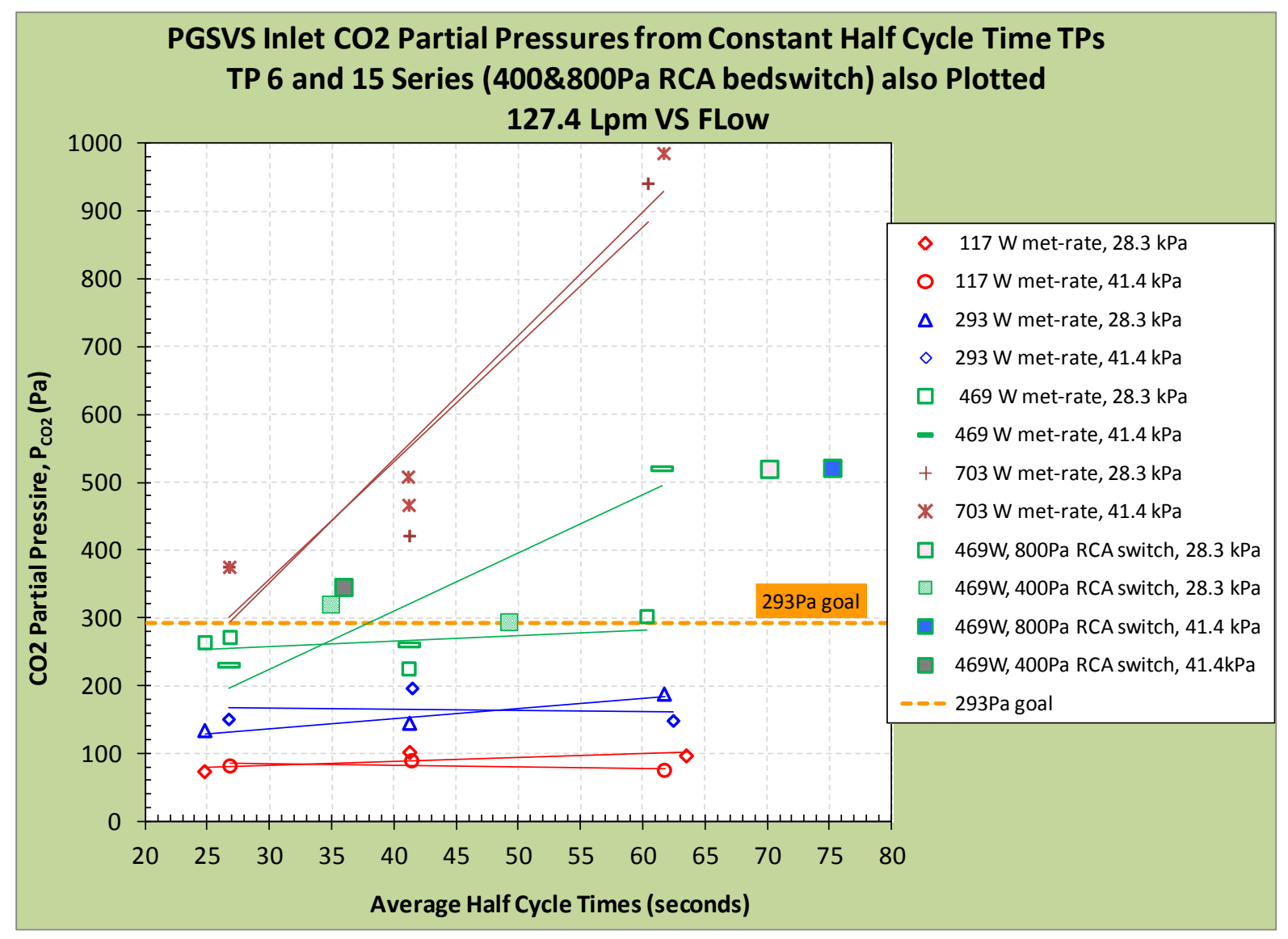

Figure 22. PGSVS inlet mean $\mathbf{P}_{\mathrm{CO} 2}$ from constant half-cycle time test points.

While remaining well below the $293 \mathrm{~Pa}$ goal as expected, the 117 and $293 \mathrm{~W}$ test series results proved surprising in that the response to varying half-cycle times was minimal. These test results suggest there is a point of marginal return for lower metabolic rates. The nominal $400 \mathrm{~Pa}$ RCA bed switch test points, TP 4R400, 5R400, and 5R400r, while not plotted provide good reference points. The $117 \mathrm{~W}$ metabolic rate, TP $4 \mathrm{R} 400$ PGSVS inlet mean $\mathrm{P}_{\mathrm{CO} 2}$ was $175 \mathrm{~Pa}$ and average half-cycle time was 708 seconds (11.8 minutes). Average values for the two $293 \mathrm{~W}$ metabolic rate/28.3 kPa TPs, 5R400 and 5R400r, were $252 \mathrm{~Pa}$ mean PGSVS inlet $\mathrm{P}_{\mathrm{CO} 2}$ and 116 seconds half-cycle time. Mean PGSVS inlet $\mathrm{CO}_{2}$ partial pressures declined $43 \%$ to $25 \%$ from the their $400 \mathrm{~Pa} \mathrm{P}_{\mathrm{CO} 2}$ test point result to the 60 -second constant half-cycle time test result for the 117 and $293 \mathrm{~W}$ cases, respectively. The data suggest, very loosely, that the point of marginal return is close to 60 seconds in the $293 \mathrm{~W}$ metabolic rate case and a much longer time frame in the $117 \mathrm{~W}$ case. Many more test points would need to be conducted to fully characterize this aspect of the RCA performance.

The $469 \mathrm{~W}$ metabolic rate constant half-cycle results are interesting for the divergence between the 28.3 and 41.4 $\mathrm{kPa}$ test results. Especially noteworthy is the significant variation of the 60 -second mean PGSVS inlet $\mathrm{CO}_{2}$ partial pressures, which were 302 and $520 \mathrm{~Pa}$ for the 28.3 and $41.4 \mathrm{kPa}$ test points, respectively. It is only by plotting the 
400 and 800 Pa RCA bed switch nominal TPs $(6,15,6 \mathrm{R} 400,6 \mathrm{R} 400 \mathrm{r}, 15 \mathrm{R} 400)$ that an argument could be made that the $28.3 \mathrm{kPa} 60$ second half-cycle time test result of $302 \mathrm{~Pa}$ should be considered as an outlier. Another interpretation of the test results is that at this metabolic rate the RCA is highly sensitive and can be prone to bifurcations as shown in Fig. 22. Finally and perhaps most important with respect to the $469 \mathrm{~W}$ metabolic rate TPs is that the data strongly indicate a very short half-cycle time of 20 to 25 seconds might be necessary to meet the $293 \mathrm{~Pa}$ goal while accounting for potential scatter.

One observation regarding data in Fig. 22 is that average half-cycle times differed from the 23, 25, 40, and 60 second setpoints. It is believed these slight differences are an artifact of the DACS. The test data recording interval was set to 1 second, which, combined with occasional data processing delays, resulted in some actual half-cycle times slightly different from the setpoint. In addition, round-off error caused some variations between when the command was issued and when it was recorded.

\section{B. Results from 7-Hour Nominal Extravehicular Activity Operations Simulations}

The first 7-hour nominal EVA simulation executed was TP 67 in which the VS flow and pressure setpoints were 127.4 Lpm and $28.3 \mathrm{kPa}$, respectively, while the RCA bed switch was set to $467 \mathrm{~Pa}$ PGSVS inlet $\mathrm{P}_{\mathrm{CO} 2}$. As usual, the Thermal Subsystem pump flow target was $91 \mathrm{~kg} / \mathrm{hr}$ and SWME water outlet temperature target was $10^{\circ} \mathrm{C}\left(50^{\circ} \mathrm{F}\right)$. Figure 23 presents an overview of VS performance during TP 67 and illustrates the difficulty of maintaining the $28.3 \mathrm{kPa}$ pressure during the $900 \mathrm{~W}$ metabolic rate portions at the TP beginning and end. During the initial $900 \mathrm{~W}$ metabolic rate simulation, VS pressures rose due to the fastest allowable RCA cycling ( 20 seconds half-cycle time), which dumped excessive RCA valve motive nitrogen into the VS. The MGC rose from its initial, nominal $185 \mathrm{~g} / \mathrm{hr}$ flow rate in response to rising VS pressures. The PGSVS inlet $\mathrm{P}_{\mathrm{CO} 2}$ plotted in Fig. 23 appears to be steady during this initial $900 \mathrm{~W}$ simulation.

In contrast, the final 900 W simulation experienced rising PGSVS inlet and VS pressures. VS pressures started to stabilize, but continuously rising $\mathrm{CO}_{2}$ levels caused RCA halfcycle times to drop from 18 to 9 seconds. The allowable minimum RCA half-cycle time was changed at some point during this test point to a low value, believed to be 6 seconds. Once the RCA half-cycle time dropped from 18 to 9 seconds, the pressures spiked from approximately $36 \mathrm{kPa}$ to a peak value of 57 $\mathrm{kPa}$. The test point was then stopped early. The flat-lined MGC flow rates during the final $900 \mathrm{~W}$ simulation are

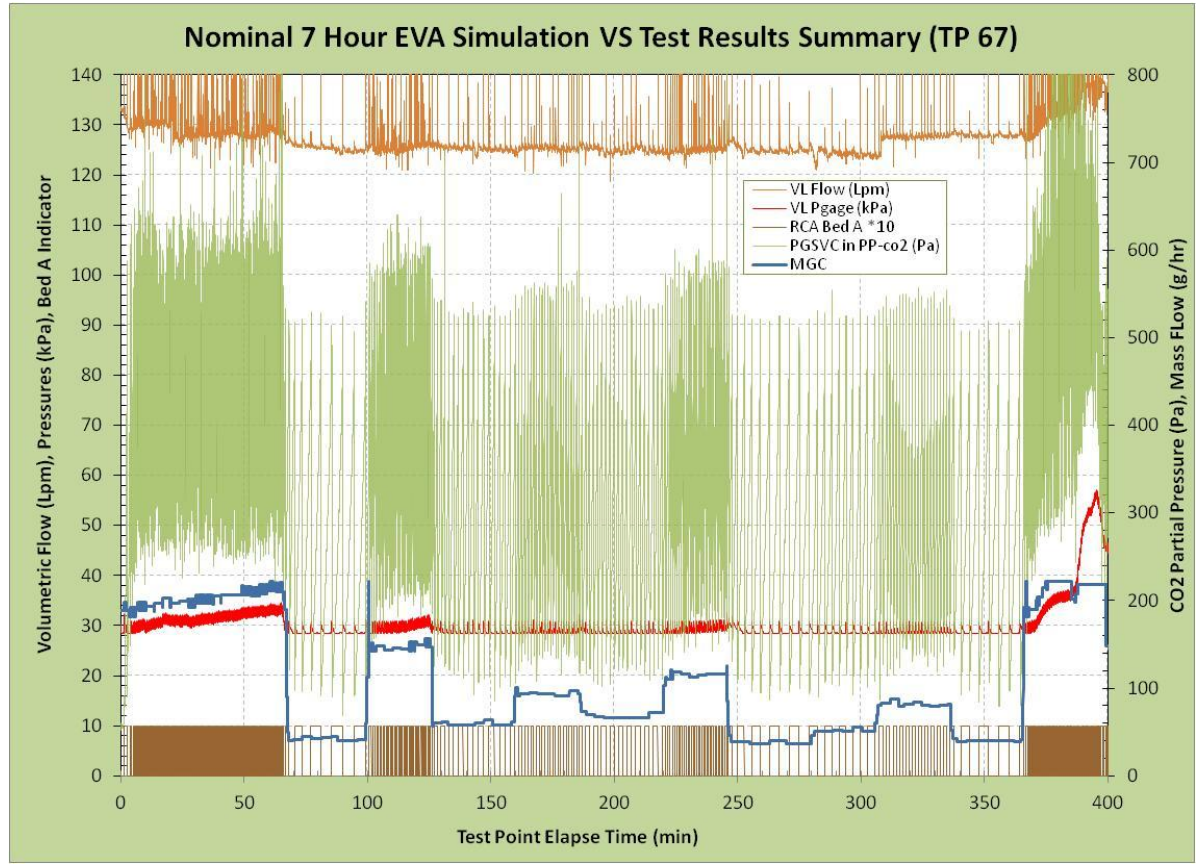

Figure 23. TP 67 nominal EVA simulation Ventilation Subsystem test results summary. unexpected because if the MGC valve was choked as planned, flow rates should have increased as the pressure spiked. It is possible the vacuum system performance was degraded at this point, causing subsonic valve flow, and thus flow sensitive to downstream conditions. Another explanation could be DACS and instrumentation faults.

Because results in Fig. 23 yield mostly a qualitative understanding of RCA cycle times and mean PGSVS inlet $\mathrm{P}_{\mathrm{CO} 2}$, an Excel macro was written to calculate the duration of each full RCA cycle and the mean PGSVS inlet $\mathrm{P}_{\mathrm{CO} 2}$ for each full RCA cycle. The results of this macro are plotted in Fig. 24 showing RCA full-cycle times ranged from 0.3 minutes (9 seconds half-cycle times) to 9.2 minutes. The reduced ullage loss advantage of the $\mathrm{P}_{\mathrm{CO} 2} \mathrm{RCA}$ switch mode is readily apparent as the RCA full-cycle times increase immediately in response to lower metabolic rates. The 
$\mathrm{CO}_{2}$ injection rates in Fig. 24 serve as a proxy for the simulated metabolic rate and to help mark actual profile changes.

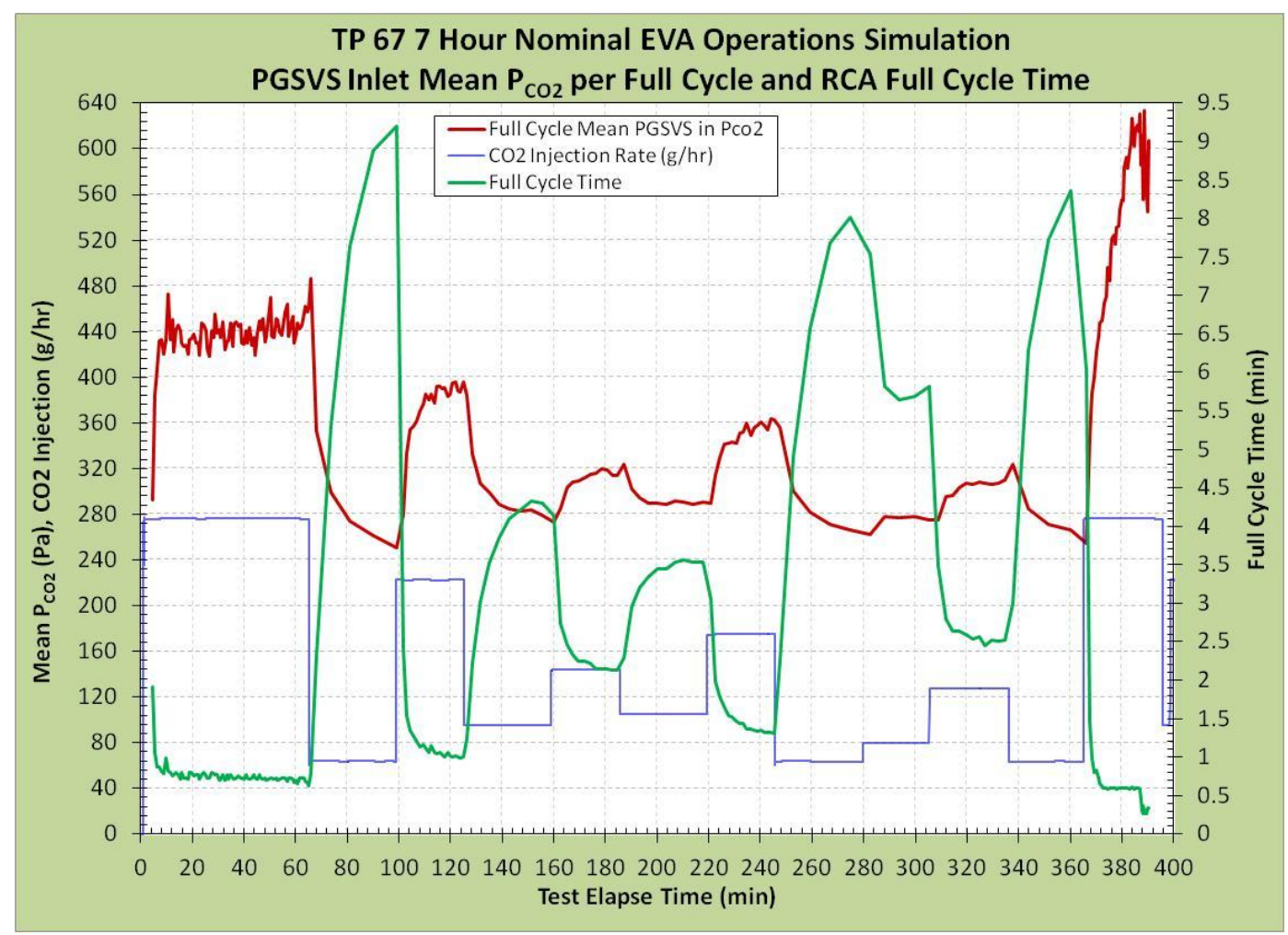

Figure 24. PGSVS inlet mean $P_{\mathrm{CO} 2}$ per full RCA cycle and RCA full-cycle time for TP 67.

Per-cycle mean PGSVS inlet $\mathrm{P}_{\mathrm{CO} 2}$ ranged from 250 to $634 \mathrm{~Pa}(1.9$ to $4.8 \mathrm{~mm} \mathrm{HG})$ with the 6.5 -hour duration simulation mean PGSVS inlet $\mathrm{P}_{\mathrm{CO} 2}$ equal to $338 \mathrm{~Pa}(2.5 \mathrm{~mm} \mathrm{Hg}), 15 \%$ higher than the $293 \mathrm{~Pa}(2.2 \mathrm{~mm} \mathrm{Hg})$ goal. Note this TP was the final one to evaluate the adequacy of the $467 \mathrm{~Pa}$ RCA bed switch level. Initial and final $900 \mathrm{~W}$ simulation differences are especially obvious in Fig. 24 as the per-cycle mean PGSVS inlet $\mathrm{P}_{\mathrm{CO} 2}$ slowly increased from 430 to $480 \mathrm{~Pa}$ in the initial $900 \mathrm{~W}$ simulation and rapidly rose through this level in the final $900 \mathrm{~W}$ simulation. The cause of the final $900 \mathrm{~W}$ RCA behavior is not known at this time and should be further investigated.

Figure 25 presents an overview of TP 67 Thermal Subsystem test results by simultaneously plotting SWME heat rejection, water outlet temperature, BPV potentiometer voltage, and LCGS water flow rate and outlet temperature. Excluding spikes, SWME heat rejections ranged from 255 to $930 \mathrm{~W}$ while supplying $10^{\circ} \mathrm{C}\left(50^{\circ} \mathrm{F}\right)$ to $13^{\circ} \mathrm{C}\left(55^{\circ} \mathrm{F}\right)$ water to the LCGS. As shown by the potentiometer voltage, the SWME BPV was fully open in only three profile steps (initial $900 \mathrm{~W}, 700 \mathrm{~W}$, and final $900 \mathrm{~W}$ ), and outlet temperatures exceeded the $10^{\circ} \mathrm{C}\left(50^{\circ} \mathrm{F}\right)$ goal. In all other profile steps, the SWME cooled the water as needed with margin. Finally, the inverse relation between SWME heat rejection and LCGS outlet temperature was a consequence of varying the flow to the LCGS to mimic what has been observed in current EVAs with the EMU. Typically, the crew desires less flow and warmer water when their metabolic rates drop. LCGS outlet temperatures ranged from $14.5^{\circ} \mathrm{C}\left(58.1^{\circ} \mathrm{F}\right)$ to $25.4^{\circ} \mathrm{C}\left(77.7^{\circ} \mathrm{F}\right)$ during $\mathrm{TP} 67$. 


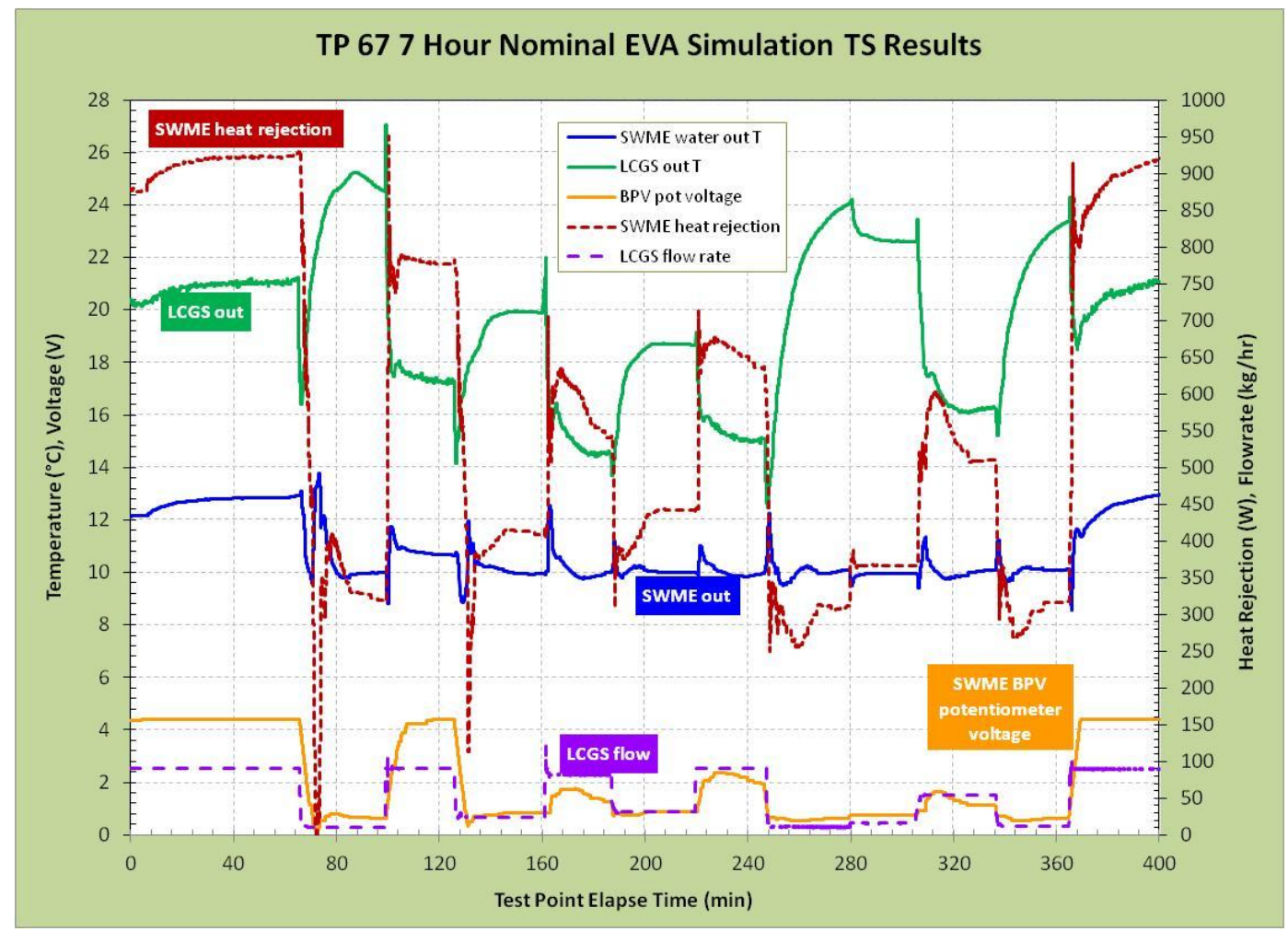

Figure 25. TP 67 nominal EVA simulation Thermal Subsystem test results.

TP 68 was the first test point in which the RCA bed switch level was set to $400 \mathrm{~Pa}$. In addition, TP 68 marked the beginning of the practice of adjusting the MGC as needed to maintain VS pressure. While not presented, plotted TP 68 Ventilation Subsystem results show an overall smoother performance than that of TP 67 with respect to maintaining setpoint pressures. Only during the $700 \mathrm{~W}$ step did the VS pressure rise appreciably from the $41.4 \mathrm{kPa}$ setpoint to approximately $46 \mathrm{kPa}$. Adjustments to the MGC brought the VS pressures back to setpoint. Another example of the improved test operations during TP 68 was the extension of the final $530 \mathrm{~W}$ step by an extra 25 minutes while Thermal Subsystem operations were wound down.

RCA full-cycle times for TP 68 ranged from 46 seconds ( 23 seconds half-cycle) to 7.9 minutes, as shown in Fig. 26. Cycle mean PGSVS inlet $\mathrm{P}_{\mathrm{CO} 2}$ ranged from $220 \mathrm{~Pa}(1.7 \mathrm{~mm} \mathrm{Hg})$ during each $200 \mathrm{~W}$ step to a peak of $442 \mathrm{~Pa}$ $\left(3.3 \mathrm{~mm} \mathrm{Hg}\right.$ ) during the single $870 \mathrm{~W}$ metabolic rate step. The mean PGSVS inlet $\mathrm{P}_{\mathrm{CO} 2}$ for the entire EVA simulation was $290 \mathrm{~Pa}$, meeting the $293 \mathrm{~Pa}$ goal $(2.2 \mathrm{~mm} \mathrm{Hg})$. 


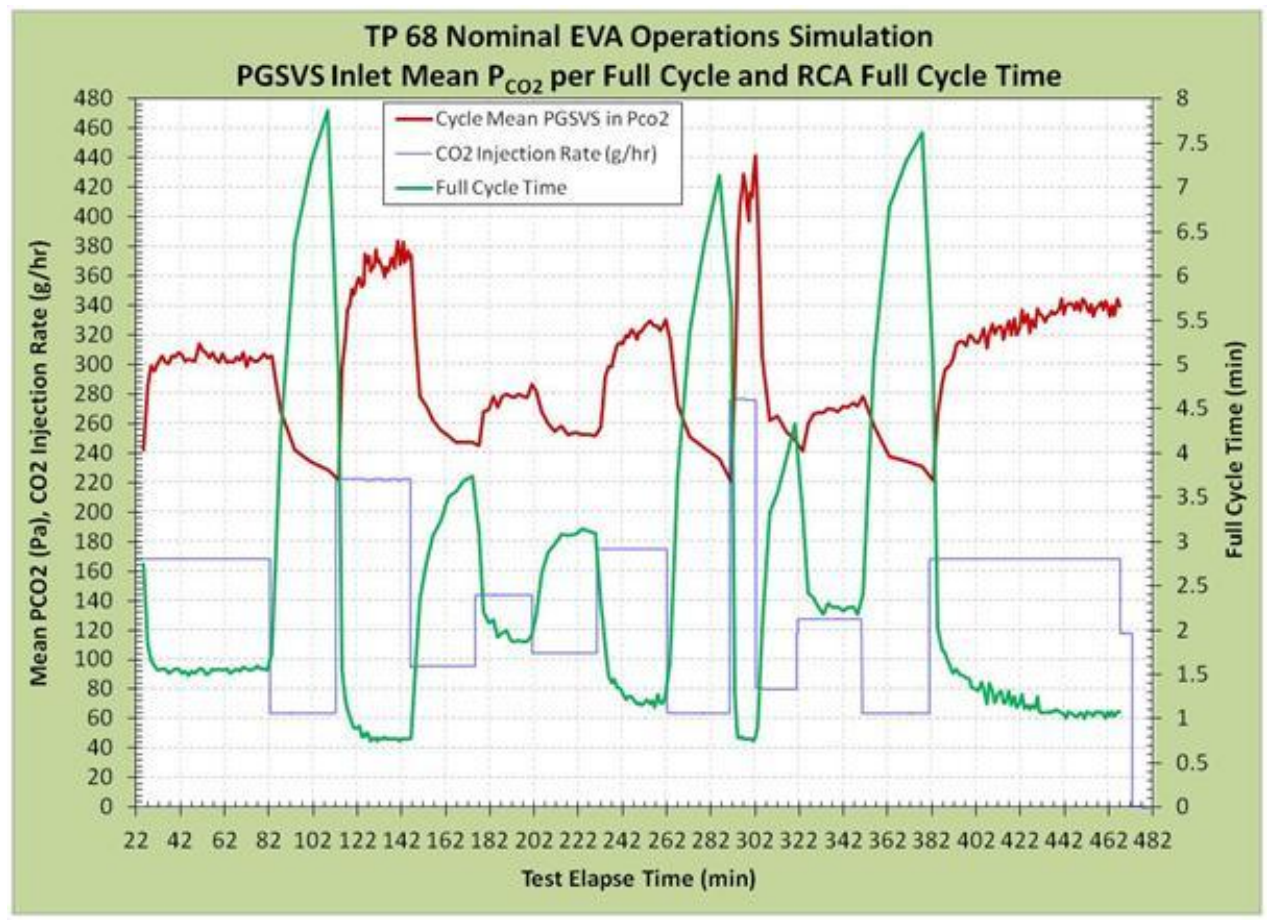

Figure 26. PGSVS inlet mean $P_{\mathrm{CO} 2}$ per full RCA cycle and RCA full-cycle time for TP 68.

As in TP 67, the mean PGSVS inlet $\mathrm{P}_{\mathrm{CO} 2}$ during the final, hour-long, high-metabolic-rate step was higher (345 $\mathrm{Pa})$ than during the identical initial step $(\sim 310 \mathrm{~Pa})$. Unlike TP 67 , the mean $\mathrm{P}_{\mathrm{CO} 2}$ stabilized without any external adjustments. RCA full-cycle times averaged approximately 1.5 minutes during the initial step and approximately 1 minute during the final step. These test results suggest the RCA desorption had degraded over the course of the EVA simulation with the cause currently unknown and worth investigating.

Figure 27 presents a summary of TP 68 Thermal Subsystem test results. Peak SWME heat rejection during the initial and final high metabolic rate steps ranged from 929 to $949 \mathrm{~W}$ with corresponding SWME outlet temperatures of $12.8^{\circ} \mathrm{C}\left(55^{\circ} \mathrm{F}\right)$ and $13.3^{\circ} \mathrm{C}\left(55.9^{\circ} \mathrm{F}\right)$, respectively. The SWME BPV was fully opened during these steps, as indicated by the approximately 4.5 SWME BPV potentiometer voltage. In addition, the BPV was fully open during the $700 \mathrm{~W}$ and $870 \mathrm{~W}$ steps with SWME outlet temperatures steadying at 10.8 in the former and rising to 11.8 in the latter. LCGS flow rates and outlet temperatures ranged from 11 to $90.2 \mathrm{~kg} / \mathrm{hr}$ and $14.8^{\circ} \mathrm{C}\left(58.6^{\circ} \mathrm{F}\right)$ to $25.5^{\circ} \mathrm{C}$ $\left(77.9^{\circ} \mathrm{F}\right)$, respectively. Note the LCGS flow rate maximum will always be less than the pump flow rate (SWME inlet flow) due to the evaporation of a small quantity of the water coolant when the SWME BPV is open. For example, a $949 \mathrm{~W}$ heat load will evaporate water at a rate of $1.4 \mathrm{~kg} / \mathrm{hr}(3.1 \mathrm{lbm} / \mathrm{hr})$. 


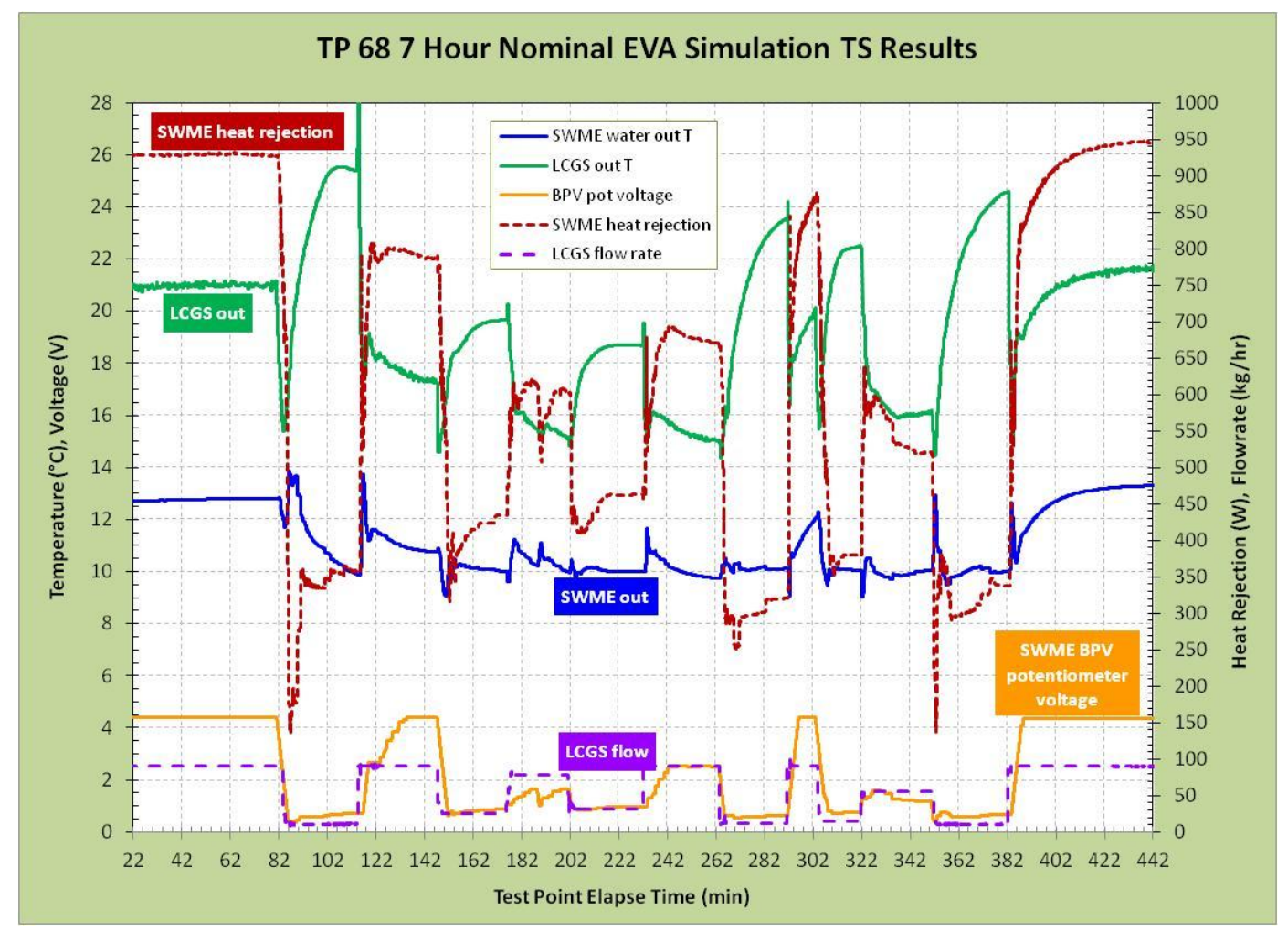

Figure 27. TP 68 EVA simulation Thermal Subsystem results summary.

In a qualitative sense, this test point profile appeared more challenging than TP 67 for the SWME with respect to maintaining $10^{\circ} \mathrm{C}\left(50^{\circ} \mathrm{F}\right)$ outlet water. The transition from the profile first step to second step in which the SWME heat rejection dropped from a steady $929 \mathrm{~W}$ to a final $359 \mathrm{~W}$ provides a good example. During the transition, however, the SWME heat rejection fell to a low of $136 \mathrm{~W}$ and the SWME outlet temperature started to increase away from the $10^{\circ} \mathrm{C}\left(50^{\circ} \mathrm{F}\right)$ target. This was caused by the test operator closing the BPV too far as indicated by the BPV potentiometer voltage. But relative to the valve full travel, the overshoot was small, thus illustrating the known sensitive heat rejection/valve position characteristic of the current SWME design. A similar overshoot occurred during the transition from the $11^{\text {th }}$ step to the $12^{\text {th }}$ step. These results are considered very positive for illustrating the known challenges regarding SWME BPV control and for providing a baseline profile to use in future automated SWME BPV control tests.

\section{Purge Simulations Test Results}

The purge simulations were intended to characterize the Oxygen Subsystem performance over a range of purge flow rates that bound current EMU helmet and suit purge flow rates and then some. Per Ref. 16, the EMU helmet purge flow specification is $1.13 \mathrm{~kg} / \mathrm{hr}(2.5 \mathrm{lbm} / \mathrm{hr})$ with the helmet gas absolute pressure at $23.1 \mathrm{kPa}(3.35 \mathrm{psia})$ and the suit purge flow specification is 2.15 to $2.26 \mathrm{~kg} . \mathrm{hr}$ ( 4.74 to $4.986 \mathrm{lbm} / \mathrm{hr}$ ) at $23.79 \mathrm{kPa}$ (3.45 psia) gas absolute pressure. Four purge flow rate setpoints of $0.5,1.15,2.5$, and $4.5 \mathrm{~kg} / \mathrm{hr}$ were selected for this test series and were achieved by adjusting the purge valve until flow rates reached their target within acceptable tolerances.

A detailed look of the $4.5 \mathrm{~kg} / \mathrm{hr}(9.9 \mathrm{lb} / \mathrm{hr})$ purge flow test results presented in Fig. 28 contains many interesting features. The Oxygen Subsystem pressure measurements, denoted OS $\mathrm{P}_{\Delta}$ in the figure, were $21.6 \mathrm{kPa}$ compared to an expected $25.5 \mathrm{kPa}$ during the first part of the purge. This TP was the only one in which the demanded flow exceeded the POA maximum capability and the SOA had to supplement. A consequence was that the POA could not maintain pressures at its $28.3 \mathrm{kPa}$ setpoint and pressure regulation was provided by the SOR. The SOR started to flow nitrogen when the Oxygen Subsystem $\mathrm{P}_{\Delta}$ reached $24 \mathrm{kPa}$ with $\mathrm{SOA}$ flow increasing to $1.7 \mathrm{~kg} / \mathrm{hr} 10$ seconds after the SOR cracked open. Another 9 seconds later, the SOA was delivering $1.9 \mathrm{~kg} / \mathrm{hr}$ of nitrogen and the OS $\mathrm{P}_{\Delta}$ 
was $21.6 \mathrm{kPa}$. Based on the measured SOR cracking pressure of $24 \mathrm{kPa}$, it is possible the SOR setpoint was set too low and could partially explain the lower-than-expected suit pressure $\left(\mathrm{OS}_{\Delta}\right)$ measurements.

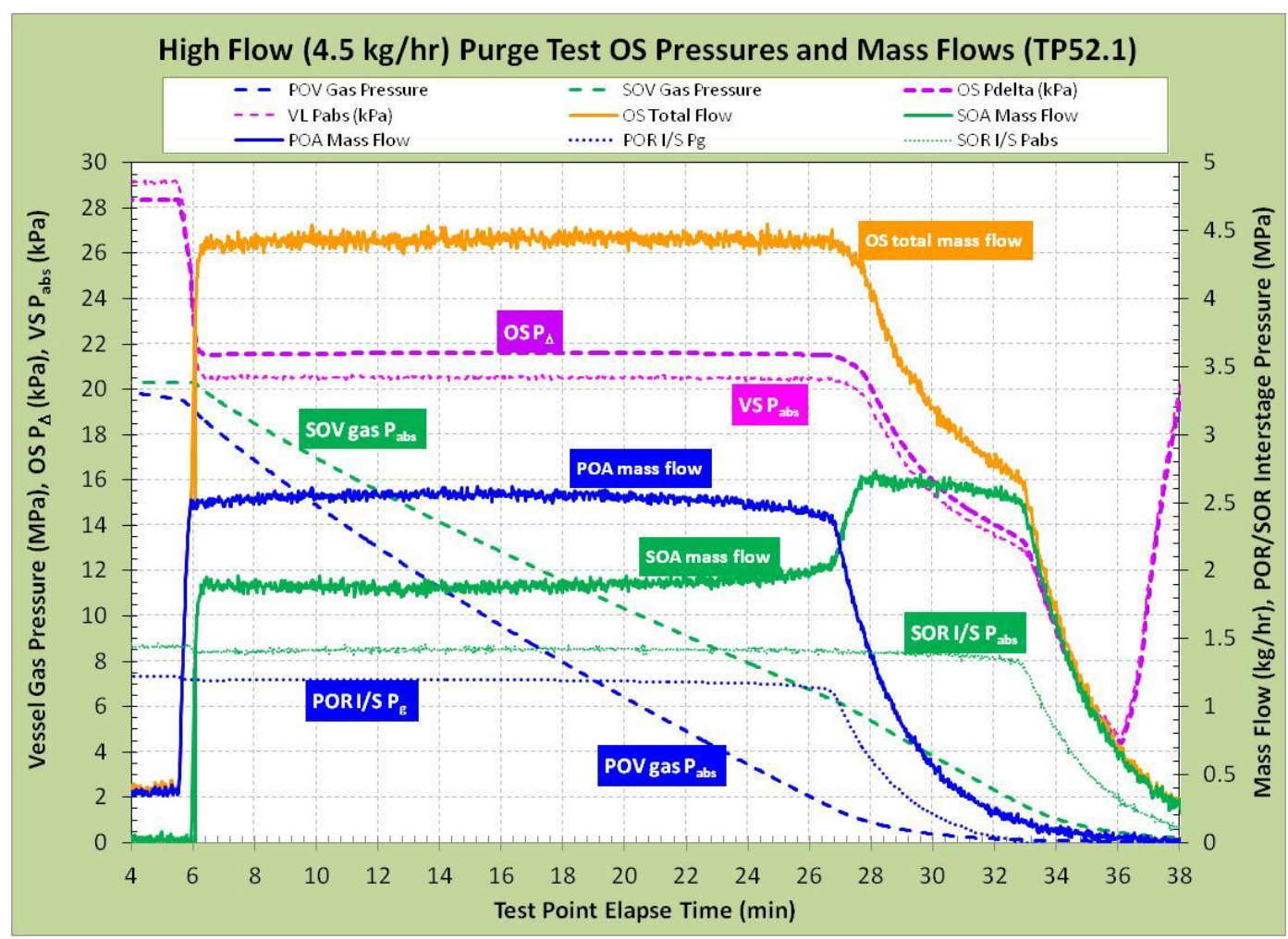

Figure 28. Test results from the $4.5 \mathrm{~kg} / \mathrm{hr}$ purge flow test (TP 52.1).

During the steady flow phase, the POR and SOR interstage pressures remained constant at $1.4 \mathrm{MPa}$ absolute and 1.2 $\mathrm{MPa}$ gauge during discharge until the POV and SOV pressures reached 1.5 and $1.7 \mathrm{MPa}$, respectively. The subsequent sharp regulator interstage pressure declines naturally coincided with sharp declines in respective mass flow rates as the supply gas no longer had the requisite pressure energy to overcome all of the flow resistances in the two stage regulators. In response to decreasing POA flow rates, SOA flow rates rose to $2.7 \mathrm{~kg} / \mathrm{hr}$ but could not maintain the VS pressures, which dropped to $13.2 \mathrm{kPa}$ absolute before SOA flow dropped precipitously at 32.9 minutes test elapse time.

The two Oxygen Assemblies produced a total nitrogen flow of $4.45 \mathrm{~kg} / \mathrm{hr}$ for a total of 20.1 minutes. The shapes of the POA and SOA mass flow curves mirror each other during the steady flow phase when the POA mass flow curve has a slight downward parabolic shape. It is thought the decreasing gas temperature might explain the POA mass flow curve. The SOA mass flow curve simply results from the SOR opening up in response to the slight decrease in POA mass flows.

POA test temperatures for TP 52.1 are plotted in Fig. 29 and show the POV gas temperature reached the instantaneous minimum temperature of $-2^{\circ} \mathrm{C}\left(28^{\circ} \mathrm{F}\right)$ that coincided with the time at which POA flow drops precipitously and POV gas pressure decline starts to slow significantly. POV wall temperatures reached a minimum of $11^{\circ} \mathrm{C}\left(52^{\circ} \mathrm{F}\right)$, resulting in a maximum temperature difference between the POV gas and wall of $13^{\circ} \mathrm{C}\left(55^{\circ} \mathrm{F}\right)$. These temperatures are very benign relative to predicted POV gas temperature drops of $162^{\circ} \mathrm{C}\left(324^{\circ} \mathrm{F}\right)$ and $70^{\circ} \mathrm{C}$ $\left(158^{\circ} \mathrm{F}\right)$ based on simple adiabatic gas expansion calculations and more rigorous transient non-adiabatic Oxygen Subsystem discharging analyses, ${ }^{17}$ respectively. Downstream of the POV, POR reactions to the discharge cooling can be seen in the POR body temperature decrease to $20^{\circ} \mathrm{C}\left(68^{\circ} \mathrm{F}\right)$. The POR motor starts higher than the POR body due to POR motor operations, as indicated by the POR electrical power, and then drops to just above $23^{\circ} \mathrm{C}\left(73^{\circ} \mathrm{F}\right)$. POR exit gas temperatures are minimally affected, dropping to a minimum of $23.5^{\circ} \mathrm{C}\left(74.3^{\circ} \mathrm{F}\right)$. Finally, SOA instantaneous minimum temperatures ranged from $-2^{\circ} \mathrm{C}\left(28^{\circ} \mathrm{F}\right)$ for the SOV gas to $24^{\circ} \mathrm{C}\left(75^{\circ} \mathrm{F}\right)$ for the SOR motor. 


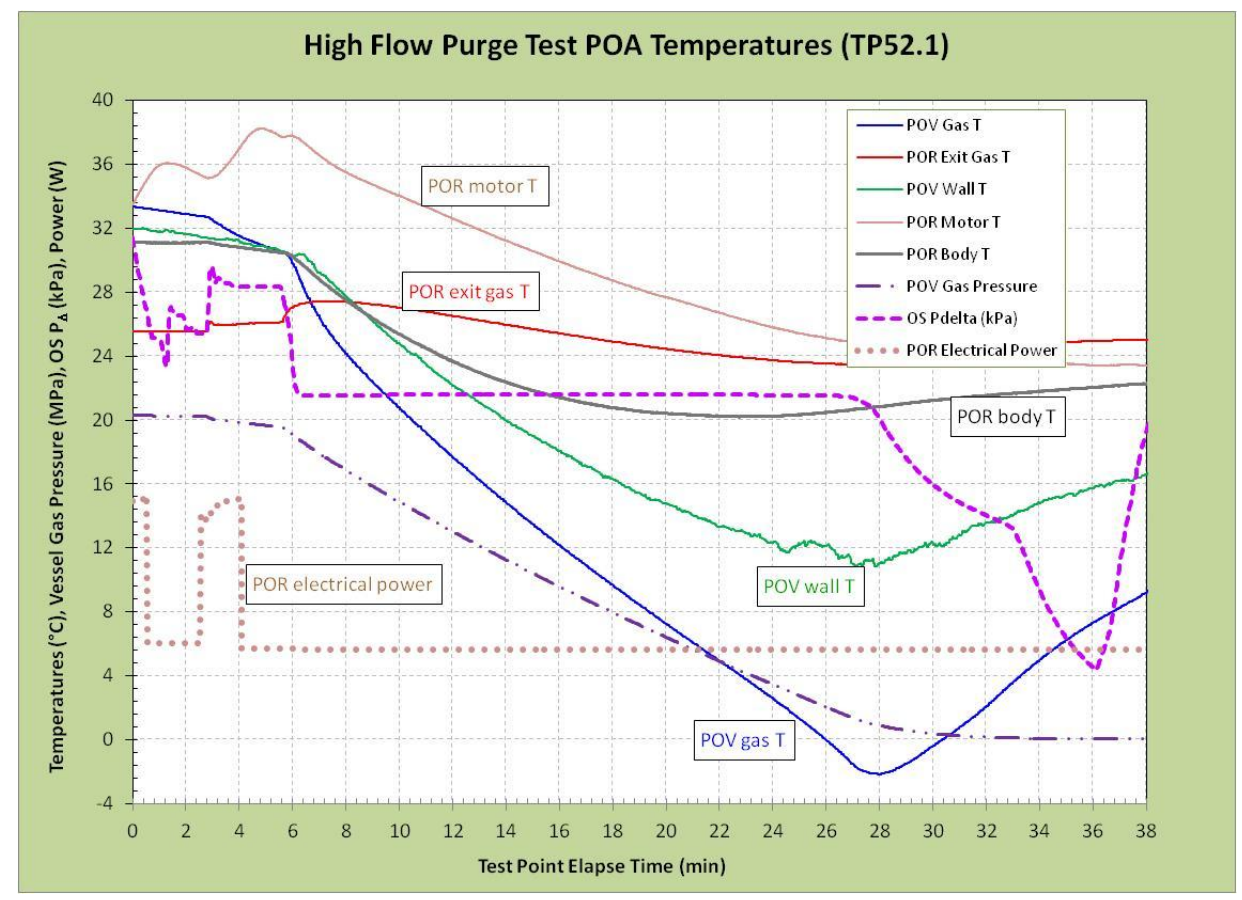

Figure 29. POA temperatures during TP $52.1(4.5 \mathrm{~kg} / \mathrm{hr}$ purge flow TP).

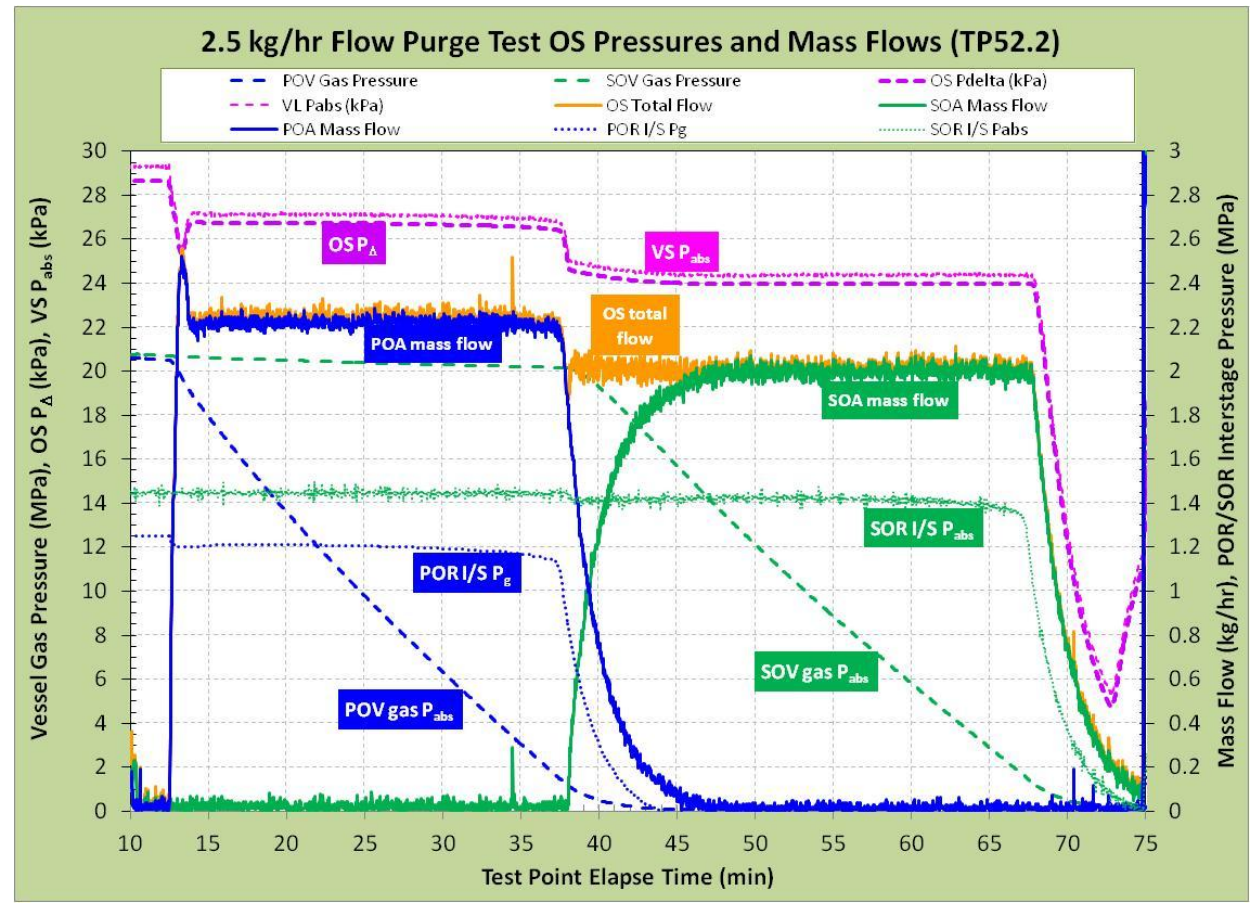

Figure 30. Pressures and mass flows from the $2.5 \mathrm{~kg} / \mathrm{hr}$ purge flow test (TP 52.2).

Results from the $2.5 \mathrm{~kg} / \mathrm{hr}(5.5 \mathrm{lbm} / \mathrm{hr})$ test, TP 52.2, are plotted in Fig. 30 and show that, unlike TP 52.1, purge flow was initially provided by the POA. The POR maintained a suit pressure ( $\mathrm{OS}_{\Delta}$ ) of $26.7 \mathrm{kPa}$ while flowing 2.2 $\mathrm{kg} / \mathrm{hr}$ of nitrogen for 22 minutes before its flow rate started to drop sharply. The SOA very smoothly compensated for the decreasing POA flow rates by ramping its flow to $1.9 \mathrm{~kg} / \mathrm{hr}$ over 7 minutes after cracking open. SOR flow 
then leveled around $2 \mathrm{~kg} / \mathrm{hr}$ while a suit pressure of $24 \mathrm{kPa}$ was maintained for an additional 22.5 minutes. The SOR cracked open when the OS $\mathrm{P}_{\Delta}$ measurement reached $24.7 \mathrm{kPa}$.

Temperature profiles in TP 52.2 were very similar to results presented in Fig. 29, with the POV gas and wall temperatures reaching $-1^{\circ} \mathrm{C}\left(30^{\circ} \mathrm{F}\right)$ and $12^{\circ} \mathrm{C}\left(54^{\circ} \mathrm{F}\right)$, respectively. SOV gas and wall temperatures reached instantaneous minimums of $-2^{\circ} \mathrm{C}\left(28^{\circ} \mathrm{F}\right)$ and $13^{\circ} \mathrm{C}\left(55^{\circ} \mathrm{F}\right)$, respectively. Oxygen Subsystem regulators exit gas temperatures ranged from $20^{\circ} \mathrm{C}\left(68^{\circ} \mathrm{F}\right)$ to $25^{\circ} \mathrm{C}\left(77^{\circ} \mathrm{F}\right)$ throughout the $2.5 \mathrm{~kg} / \mathrm{hr}$ purge flow test.

Oxygen Subsystem performance in the 1.15 and $0.5 \mathrm{~kg} / \mathrm{hr}$ purge flow test points (TP 52.3 and 52.4) was very similar to that in the $2.5 \mathrm{~kg} / \mathrm{hr}$ purge flow case (TP 52.1), just on a longer time scale due to the lower flow rates. The transition in the $0.5 \mathrm{~kg} / \mathrm{hr}$ purge flow test point, however, proved interesting and is plotted in Fig. 31. Of key interest is the drop in Oxygen Subsystem total flow rate to a minimum of $0.3 \mathrm{~kg} / \mathrm{hr}$ at 120.5 minutes elapse time, the moment the SOR cracked open. This minimum flow rate represents a $40 \%$ drop from the POA $0.5 \mathrm{~kg} / \mathrm{hr}$ flow. The SOA reestablished $0.5 \mathrm{~kg} / \mathrm{hr}$ flow within 45 seconds of cracking open. While attention is called to this flow spike, it is left to future analyses and discussion to determine its significance.

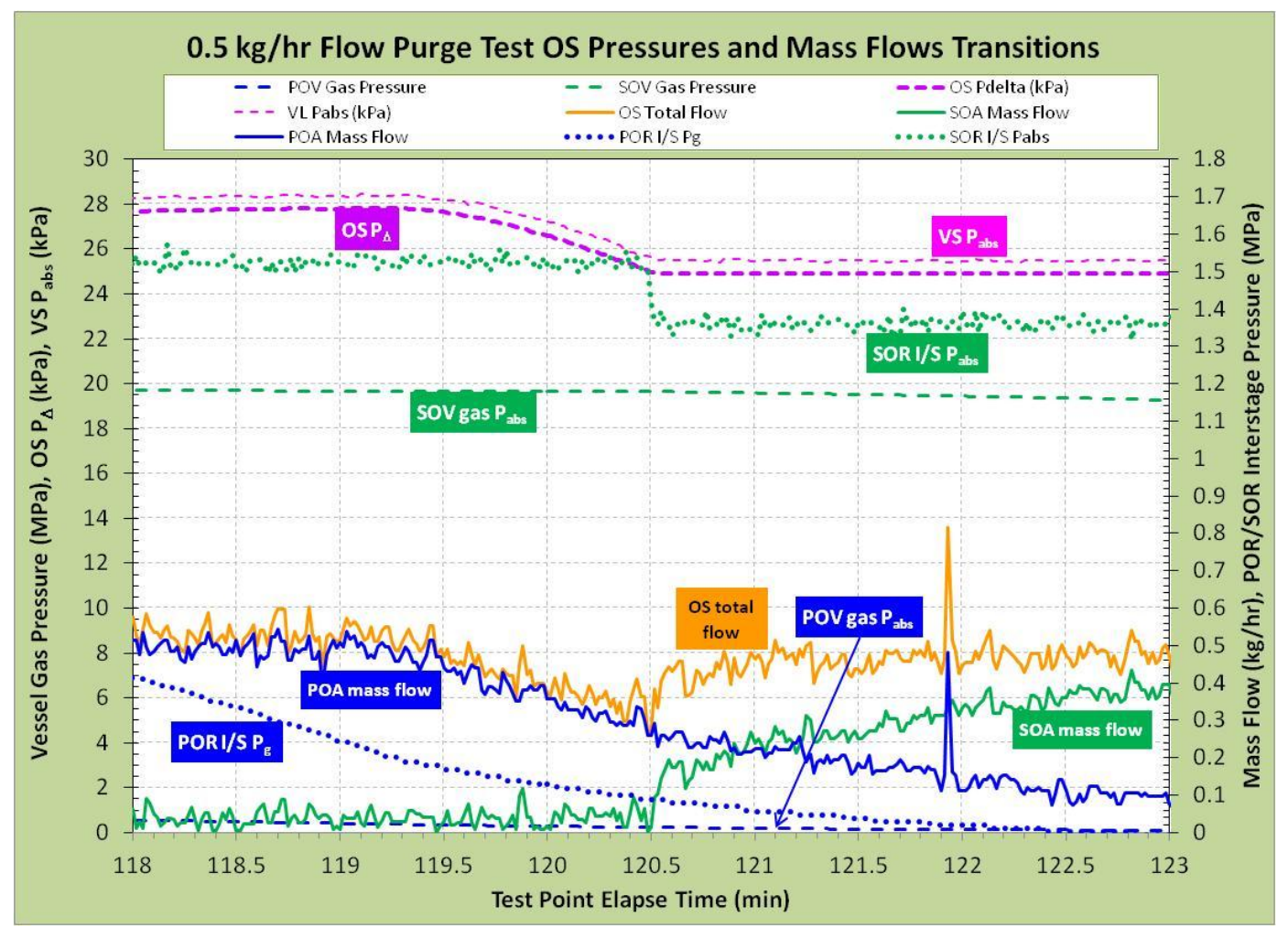

Figure 31. Oxygen Subsystem pressure and flow transitions during $0.5 \mathrm{~kg} / \mathrm{hr}$ purge flow test point.

\section{Conclusions and Forward Work}

Many years of advanced PLSS system and component development culminated in the fabrication and successful operation of an integrated PLSS test bed, denoted PLSS 1.0. PLSS 1.0 was built to investigate the functionality of the Advanced PLSS while incorporating available PLSS technology development components. The PLSS technology components integral to the PLSS 1.0 test bed include the Oxygen Subsystem primary and secondary oxygen regulators, Ventilation Subsystem fan and RCA swing bed $\mathrm{CO}_{2}$ and $\mathrm{H}_{2} \mathrm{O}$ adsorption device, and Thermal Subsystem SWME water evaporative heat rejection unit.

An extensive database of PLSS 1.0 test results was generated from the successful operation of 168 test points completed over 44 days of testing. Fundamentally, the PLSS 1.0 test results show that the Advanced PLSS, as implemented, demonstrated the capabilities to provide the key life support functions of suit pressure regulation, $\mathrm{CO}_{2}$ and $\mathrm{H}_{2} \mathrm{O}$ removal, thermal control and contingency purge operations. Results from steady state testing illustrated nominal PLSS 1.0 performance with respect to simulated crew member metabolic rates ranging from 88 to $586 \mathrm{~W}$ 
(300 to $2000 \mathrm{Btu} / \mathrm{hr}$ ) and near nominal PLSS performance in the $879 \mathrm{~W}(3000 \mathrm{Btu} / \mathrm{hr}$ ) metabolic rate test point. Steady state test results also illustrated PLSS performance with respect to contingency control modes. In particular, $\mathrm{CO}_{2}$ control was investigated with respect to operating the RCA at a constant half cycle time versus the nominal operational mode of switching the RCA based on the suit inlet $\mathrm{P}_{\mathrm{CO} 2}$. Transient test point results showed the PLSS successfully responded to simulated crew metabolic rate step changes during 7-hour nominal EVA simulations and also maintained suit pressures during simulated purge operations in which the purge flow rates ranged from 0.5 to $4.5 \mathrm{~kg} / \mathrm{hr}$ ( 1.1 to $9.9 \mathrm{lbm} / \mathrm{hr}$ ). Finally, PLSS 1.0 testing that investigated specific technology component performance such as $\mathrm{CO}_{2}$ control as a function of adverse RCA vacuum pressures or SWME long term performance were not presented in this paper, but are covered in other ICES 2012 papers.

The follow-on Advanced PLSS test, denoted PLSS 2.0, is currently in the active planning stages and has the primary objective of testing an integrated Advanced PLSS that is packaged within an expected flight volumetric footprint. In addition to dramatically reducing the packaging volume relative to the PLSS 1.0 test bed, PLSS 2.0 objectives include implementing additional technology components including the next generation variable setpoint oxygen regulator, Caution, Warning, and Control System avionics, $\mathrm{CO}_{2} / \mathrm{H}_{2} \mathrm{O} / \mathrm{O}_{2}$ gas constituent analyzer, Ventilation Loop flow rate sensor, Ventilation Loop/Thermal Loop gas/water heat exchanger, Thermal Loop water pump, Thermal Loop feedwater water supply assembly, and Auxillary Thermal Control Loop. The last item is notable because it represents a potential upgrade to the Advanced PLSS schematic that will provide contingency cooling via a fully redundant water system, thus reducing the cooling requirements imposed on the oxygen purge flow that effectively size the oxygen vessels. It is believed a more robust PLSS will result by reducing emergency oxygen mass requirements and extending emergency operations durations.

\section{References}

${ }^{1}$ Barnes, B., and Conger, B., "PLSS Baseline Schematics and Internal Interfaces," Revision C, CTSD-CX-5117, JSC-65563, NASA-JSC, September 2010.

${ }^{2}$ Campbell, C., "Technology Development Specification for the Primary Oxygen Regulator (POR)," CTSD-CX-0040, Crew and Thermal Division, Engineering Directorate, NASA-JSC, 15 June 2009.

${ }^{3}$ Campbell, C., "Technology Development Specification for the Secondary Oxygen Regulator (SOR)," CTSD-CX-0069, Crew and Thermal Division, Engineering Directorate, NASA-JSC, 15 June 2009.

${ }^{4}$ Campbell, C., "Technology Development Plan for the Primary Oxygen Regulator (POR)," CTSD-CX-0041, Crew and Thermal Division, Engineering Directorate, NASA-JSC, 1 June 2010.

${ }^{5}$ Paul, H., Converse, D., Dionne, S., and Moser, J., "Development of a Fan for Future Space Suit Applications," AIAA-20106132, $40^{\text {th }}$ International Conference on Environmental Systems, American Institute of Aeronautics and Astronautics, July 2010.

${ }^{6}$ Martin, D., "Portable Life Support Systems (PLSS) Ventilation Subsystem Fan Performance Test Report," CTSD-CX-5517, NASA-JSC, 9 July 2010.

${ }^{7}$ Papale, W. and Paul, H., "Development Status of an EVA-sized Cycling Amine Bed System for Spacesuit Carbon Dioxide and Humidity Removal," SAE Technical Paper 2007-01-3272, 37 $7^{\text {th }}$ International Conference on Environmental Systems, July 2007.

${ }^{8}$ McMillin, S., Broerman, C., Swickrath, M., and Anderson, M., "Testing and Results of Vacuum Swing Adsorption Units for Spacesuit Carbon Dioxide and Humidity Control," AIAA-2011-5244, 41 ${ }^{\text {st }}$ International Conference on Environmental Systems, American Institute of Aeronautics and Astronautics, July 2011.

${ }^{9}$ Swickrath, M., Anderson, M., McMillin, S., and Broerman, C., "Simulation and Analysis of Vacuum Swing Adsorption Units for Spacesuit Carbon Dioxide and Humidity Control," AIAA-2011-5243, 41 ${ }^{\text {st }}$ International Conference on Environmental Systems, American Institute of Aeronautics and Astronautics, July 2011.

${ }^{10}$ Bue, G. and et. al., "Hollow Fiber Flight Prototype Spacesuit Water Membrane Evaporator Design and Testing," AIAA-20115259, $41^{\text {st }}$ International Conference on Environmental Systems, American Institute of Aeronautics and Astronautics, July 2011.

${ }^{11}$ Bronkhorst High-Tech B. V. vapor delivery systems website page, http://www.bronkhorst.com/en/products/vapour_delivery_systems/, Bronkhorst USA Inc., Bethlehem, PA, 610-8666750 .

${ }^{12}$ Lin, C., "SINFLO Thermal Model for Simulation of a Shuttle Extravehicular Mobility Unit," LEC-12670, JSC-14445, Lockheed Electronics Company, Inc., August 1978.

${ }^{13}$ Law, J., Watkins S., and Alexander, D., "In-Flight Carbon Dioxide Exposures and Related Symptoms: Associations, Susceptibility, and Operational Implications,” TP-2010-216126, NASA, June 2010.

${ }^{14}$ Barnes, B., Pinckney, J., and Conger, B., "Portable Life Support Subsystem Thermal Hydraulic Performance Analysis," JSCCN-20896, Thermal and Fluids Analysis Workshop 2010 paper, August 2010.

15“"Constellation Program Human-Systems Integration Requirements," Revision C, CxP 70024, NASA, 6 March 2009.

16،NASA EMU Data Book,” Revision M, EMU1-5038, Hamilton Sundstrand, September, 2007. 
${ }^{17}$ Navarro, M., "Detail Thermal/Fluid Model Suit Purge Cases,” presentation, Thermal and Environmental Analysis Section (4470), Jacobs Technology-ESCG, 15 April 2009. 